\title{
Lusioersily
}

\section{Reaction Mechanism of the Metal Precursor Pulse in Plasma-Enhanced Atomic Layer Deposition of Cobalt and the Role of Surface Facets}

Liu, J., Lu, H., Zhang, D. W., \& Nolan, M. (2020). Reaction Mechanism of the Metal Precursor Pulse in PlasmaEnhanced Atomic Layer Deposition of Cobalt and the Role of Surface Facets. Journal Of Physical Chemistry C 124(22), 11990-12000. https://doi.org/10.1021/acs.jpcc.0c02976

Link to publication record in Ulster University Research Portal

Published in:

Journal Of Physical Chemistry C

Publication Status:

Published (in print/issue): 15/05/2020

DOI:

10.1021/acs.jpcc.0c02976

Document Version

Author Accepted version

\section{General rights}

Copyright for the publications made accessible via Ulster University's Research Portal is retained by the author(s) and / or other copyright owners and it is a condition of accessing these publications that users recognise and abide by the legal requirements associated with these rights.

\section{Take down policy}

The Research Portal is Ulster University's institutional repository that provides access to Ulster's research outputs. Every effort has been made to ensure that content in the Research Portal does not infringe any person's rights, or applicable UK laws. If you discover content in the Research Portal that you believe breaches copyright or violates any law, please contact pure-support@ulster.ac.uk. 


\title{
Reaction Mechanism of the Metal Precursor Pulse in Plasma- \\ Enhanced Atomic Layer Deposition of Cobalt and the Role of \\ Surface Facet
}

\author{
Ji Liu ${ }^{\mathrm{a}}$, Hongliang Lu ${ }^{\mathrm{b}}$, and David Wei Zhang ${ }^{\mathrm{b}}$, Michael Nolan ${ }^{\mathrm{a}, *}$ \\ ${ }^{a}$ Tyndall National Institute, University College Cork, Lee Maltings, Dyke Parade, Cork, T12 \\ R5CP, Ireland \\ ${ }^{\mathrm{b}}$ State Key Laboratory of ASIC and System, Shanghai Institute of Intelligent Electronics \& \\ Systems, School of Microelectronics, Fudan University, Shanghai 200433, China
}

Corresponding author:

"E-mail: Michael.nolan@tyndall.ie. Tel: +353 0212346983 


\begin{abstract}
Cobalt is a potential candidate in replacing copper for interconnects and has been applied in the trenches and vias in semiconductor industry. A non-oxidizing reactant is required in plasmaenhanced atomic layer deposition (PE-ALD) of thin films of metals to avoid O-contamination. PEALD of Co has been demonstrated experimentally, but the growth mechanism and key reactions are not clear. In this paper, the reaction mechanism of metal cyclopentadienyl $\left(\mathrm{Cp}, \mathrm{C}_{5} \mathrm{H}_{5}\right)$ precursors $\left(\mathrm{CoCp}_{2}\right)$ and $\mathrm{NH}_{\mathrm{x}}$-terminated Co surface is studied by density functional theory (DFT) calculations. The $\mathrm{Cp}$ ligands are eliminated by $\mathrm{CpH}$ formation via a hydrogen transfer step and desorb from metal surface. The surface facet plays an important role in the reaction energies and activation barriers. The results show that on the $\mathrm{NH}_{\mathrm{x}}$-terminated surfaces corresponding to ALD operating condition (temperature range $550 \mathrm{~K}$ to $650 \mathrm{~K}$ ), the two $\mathrm{Cp}$ ligands are eliminated completely on $\operatorname{Co}(100)$ surface during the metal precursor pulse, resulting in Co atom deposited on the $\operatorname{Co}(100)$ surface. But the second $\mathrm{Cp}$ ligand reaction of hydrogen transfer is thermodynamically unfavourable on the $\mathrm{Co}(001)$ surface, resulting in CoCp fragment termination on $\mathrm{Co}(001)$ surface. The final terminations after metal precursor pulse are $3.03 \mathrm{CoCp} / \mathrm{nm}^{2}$ on $\mathrm{NH}_{\mathrm{x}^{-}}$ terminated $\mathrm{Co}(001)$ surface and $3.33 \mathrm{Co} / \mathrm{nm}^{2}$ on $\mathrm{NH}_{\mathrm{x}}$-terminated $\mathrm{Co}(100)$ surface. These final structures after metal precursor pulse are essential to model the reaction during the following $\mathrm{N}$ plasma step.
\end{abstract}




\section{Introduction}

Copper $(\mathrm{Cu})$ has been widely used in the semiconductor industry as interconnect for 20 years. ${ }^{1}$ However, continuous deposition of $\mathrm{Cu}$ films needed for interconnect in nanoelectronics is difficult and a barrier layer is required to prevent the diffusion of $\mathrm{Cu}$ into the dielectric layer and $\mathrm{Si}$ substrates. $\mathrm{Cu}$ also aggregates into 3D structures. ${ }^{2-3}$ Finding suitable barrier/liner layer is still a challenge because issues with copper reduce the electrical resistivity of the interconnect, especially for devices at nanosize dimension. One solution is to replace $\mathrm{Cu}$ with metals that do not suffer these issues. Transition metal Cobalt (Co) is important as candidates in replacing $\mathrm{Cu}$ for interconnects and has been applied in the trenches and vias with the downsizing of semiconductor devices. $^{4-6}$ There is also the question of deposition of nanoscale films, in particular on high aspect ratio structures, where different surface facets maybe present. Atomic layer deposition (ALD) is applied for conformal deposition and growth control at the atomic level, which is needed for deposition onto high aspect ratio structures. ${ }^{7-8}$ Generally, ALD consists of two self-limiting half cycles, where the reactions will stop after all available surface sites are consumed. In addition to the successful application of ALD in microelectronics and the semiconductor industry, it is further applied in the areas of catalysis and energy conversion and storage. ${ }^{5,9-10}$

For the ALD of $\mathrm{Co}, \mathrm{Cp}$ based precursors such as $\mathrm{CoCp}_{2}, \mathrm{CoCp}(\mathrm{CO})_{2}$ and $\mathrm{Co}(\mathrm{CpAMD})$ have been developed and applied. ${ }^{11-12}$ For thermal ALD of Co with metal precursor and hydrogen reactant, the required growth temperature can be as high as $350^{\circ} \mathrm{C}$, but the growth rate is as low as 0.12 $\square /$ cycle. ${ }^{13}$ With the application of plasma-enhanced ALD (PE-ALD), the temperature can be reduced to $75^{\circ} \mathrm{C}$. The reported growth cycle with $\mathrm{CoCp}_{2}$ is increased to $1.5 \square /$ cycle. ${ }^{14-15}$ For the $\mathrm{N}$-plasma source, a mixture of $\mathrm{N}_{2}$ and $\mathrm{H}_{2}$ is used and the properties of the deposited Co thin film greatly depend on the $\mathrm{N}_{2} / \mathrm{H}_{2}$ gas flow ratio. ${ }^{16-17}$ It is noted that $\mathrm{H}_{2}$ plasma alone or individual $\mathrm{N}_{2}$ 
and $\mathrm{H}_{2}$ plasma results in high resistivity and low purity Co thin films. Previous studies argue that the presence of $\mathrm{NH}_{\mathrm{x}}$ species is needed to deposit low resistivity and high purity Co thin film. ${ }^{18}$ $\mathrm{NH}_{\mathrm{x}}$ species are needed for chemisorption of metal precursor and removal of the Cp ligand. But they are not incorporated in the film, because most of the $\mathrm{N}$ may desorb in the form of either $\mathrm{NH}_{3}$ or $\mathrm{N}_{2}$. The detailed mechanism requires deeper study, but one possible reason is that highly reactive radicals from $\mathrm{N}$-plasma source should be present for successful PE-ALD of Co. The final structure and termination after the metal precursor pulse are vital and essential to model the plasma step, which is the key advance of current paper.

Density functional theory (DFT) calculations have been successfully applied to study the ALD of metals and metal oxides. ${ }^{19-22}$ Theoretically, the design and large-scale screening of precursors based on specific criteria such as the thermodynamic stability and kinetic stability have been performed in ALD modelling. ${ }^{23-24}$ DFT calculations can also be applied to reveal the reaction mechanisms and the derived growth rate serves as guideline to experiments. In the early stage, the deposition of metal oxide, such as $\mathrm{Al}_{2} \mathrm{O}_{3}$ from trimethylaluminum and $\mathrm{O}_{3} / \mathrm{H}_{2} \mathrm{O}$ as the co-reactant, has been studied theoretically. ${ }^{25-29}$ The surface hydroxyl groups are formed and their surface coverages affect the growth rate. For the deposition of metals, Elliott has proposed a mechanism for deposition of noble metals including Pd, Ir and Pt using homoleptic precursors and oxygen from DFT calculations. ${ }^{30}$ It is found that each ligand is replaced by a hydroxyl group, which can be further eliminated by Brønsted-type reaction.

The reaction mechanism using oxidizing reactant such as $\mathrm{O}_{3}$ and $\mathrm{H}_{2} \mathrm{O}$ is well-established. However, when depositing metals, O-source can promote oxidation of the metal surface and therefore cause contamination. Non-oxidizing reactants such as $\mathrm{NH}_{3}$ in PE-ALD of transition metals have been experimentally developed. A complete PE-ALD process using N-plasma is as 
follows. Firstly, it is vital to note that at the post-plasma stage, the metal surface is actually the $\mathrm{NH}_{\mathrm{x}}$-terminated metal surface. In the first half-cycle, the metal precursor $\mathrm{CoCp} 2$ reacts with $\mathrm{NH}_{\mathrm{x}}$ terminated metal surface. The $\mathrm{Cp}$ ligand is eliminated by hydrogen transfer from the surface to form $\mathrm{CpH}$, which desorbs from surface. In the second half-cycle, the plasma generated radicals such as $\mathrm{N}_{\mathrm{x}} \mathrm{H}_{\mathrm{y}}$ will react with the precursor fragment terminated metal surface and the Co atoms are deposited on the surface, which is covered by $\mathrm{NH}_{\mathrm{x}}$ groups at the end of second half cycle. In our recent published work, the nature and stability of $\mathrm{NH}_{\mathrm{x}}$-terminated metal surfaces were studied. ${ }^{31}$ The results show that at ALD operating condition (temperature range $550 \mathrm{~K}$ to $650 \mathrm{~K}$ ), on the low energy (001) surface, NH-termination is the most stable surface termination, while on the high energy (100) surface, a mixture of $\mathrm{NH}$ and $\mathrm{NH}_{2}$ is the most stable surface termination.

In this paper, we explore the reaction mechanism for the metal precursor pulse by DFT calculations. The elimination of $\mathrm{Cp}$ ligand is the key step during the metal precursor pulse. Single metal precursor $\mathrm{CoCp}_{2}$ is adsorbed on the $\mathrm{NH}_{\mathrm{x}}$-terminated surfaces ${ }^{31}$ and the hydrogen transfer step is studied in detail with calculation of proton migration barrier. After the first $\mathrm{CpH}$ formation and desorption, the possibility of the loss of second $\mathrm{Cp}$ ligand is also investigated. With the $\mathrm{NH}_{\mathrm{x}}$ terminations at ALD operating condition, on the $\mathrm{Co}(100)$ surface, the metal precursor can undergo two hydrogen transfer steps and the two Cp ligands are eliminated completely, resulting in Co atom deposition on the surface, binding to $\mathrm{N}$ atom. However, only one $\mathrm{Cp}$ ligand is eliminated on the $\mathrm{Co}(001)$ surface, resulting in $\mathrm{CoCp}$ fragments on the surface after the metal precursor pulse. The precursor coverage effect is studied with two metal precursors $\mathrm{CoCp}_{2}$ adsorbed on the surface. A neighbouring CoCp has hindered the reactivity by increasing the activation barrier of the first hydrogen transfer on $\mathrm{Co}(001)$ surface, but promoted the reactivity by lowering the activation barrier of the first hydrogen transfer on $\operatorname{Co}(100)$ surface. The determined surface coverage of final 
terminations after the metal precursor pulse are $3.03 \mathrm{CoCp} / \mathrm{nm}^{2}$ on $\mathrm{NH}_{\mathrm{x}}$-terminated $\mathrm{Co}(001)$ surface and $3.33 \mathrm{Co} / \mathrm{nm}^{2}$ on $\mathrm{NH}_{\mathrm{x}}$-terminated $\mathrm{Co}(100)$ surface.

\section{Methods and Computational Details}

All the calculations are performed on the basis of periodic spin-polarized density functional theory (DFT) within a plane wave basis set and projector augmented wave (PAW) formalism ${ }^{32}$, as implemented in the Vienna $a b$ initio simulation package (VASP 5.3) code. The generalized gradient approximation (GGA) with the parameterization of Perdrew-Burke-Ernzerhof (PBE) is used for the exchange-correlation functional. ${ }^{33-34}$ We use 9 valence electrons for Co, 5 for $\mathrm{N}, 4$ for $\mathrm{C}$, and 1 for $\mathrm{H}$. The plane wave energy cutoff is set to be $400 \mathrm{eV}$. The convergence of energy and forces are set to be $1 \times 10^{-4} \mathrm{eV}$ and $0.01 \mathrm{eV} / \square$, respectively. The bulk Co crystal structure is optimized by simultaneously relaxing the ionic positions, cell volume and cell shape at a higher plane wave energy cutoff of $550 \mathrm{eV}$ and using a Monkhorst-Pack grid k-point mesh $^{35}$ of $12 \times 12 \times$ 6. The resulting lattice constants are $\mathrm{a}=\mathrm{b}=2.49 \AA$, and $\mathrm{c}=4.03 \AA$ for Co bulk.

The deposited Co films by PE-ALD are polycrystalline and have random surface orientations after low temperature deposition. Based on our previous study ${ }^{31}$ on the stability of $\mathrm{NH} / \mathrm{NH}_{2}$ terminations, we have chosen the most stable (001) surface and a less stable but high reactivity surface, namely (100), to investigate the precursor reaction mechanism. A (4×4) supercell is used to model the (001) surface with a surface lattice of $\mathrm{a}=\mathrm{b}=9.96 \square\left(\right.$ surface area $=0.99 \mathrm{~nm}^{2}$ ), while a (3×3) supercell, with a surface lattice of $\mathrm{a}=7.47 \square, \mathrm{b}=12.10 \square\left(\right.$ surface area $\left.=0.90 \mathrm{~nm}^{2}\right)$, is used to model the (100) surface. For the $\operatorname{Co}(001)$ surface, a five-layer slab is used, with the bottom three layers fixed during the calculation; while for the $\operatorname{Co}(100)$ surface, due to zigzag structure, a fourbilayer (eight atomic layer) slab is built with the bottom two bilayers (bottom four layers) fixed during the calculations. From our previous studies, fixing these-layers is sufficient to model these 
Co surfaces. ${ }^{31}$ A k-point mesh ${ }^{35}$ of $2 \times 2 \times 1$ is used in $(4 \times 4)$ supercell and for the $(3 \times 3)$ supercell a $3 \times 2 \times 1$ mesh is used.

Our previous DFT study ${ }^{31}$ of $\mathrm{NH}_{\mathrm{x}}$ saturation coverage shows that at zero-K condition, the $\mathrm{Co}(001)$ surface is terminated with $0.67 \mathrm{ML} \mathrm{NH}$ and $0.23 \mathrm{ML} \mathrm{NH}_{2}$, which contains $10 \mathrm{NH}$ and $4 \mathrm{NH}_{2}$ in a (4×4) supercell. On the $\mathrm{Co}(100)$ surface, the termination is $1 \mathrm{ML} \mathrm{NH}$ and $1 \mathrm{ML} \mathrm{NH} \mathrm{NH}_{2}$ due to the trench structure, which contains $9 \mathrm{NH}$ and $9 \mathrm{NH}_{2}$ in $(3 \times 3)$ supercell. The saturation coverages are summarized in Table 1. The configurations of the $\mathrm{NH}_{\mathrm{x}}$-terminated Co surfaces at zero-K condition are shown in Figure 1(a)-(b).

Table 1. The calculated saturation coverages on Co (001) and (100) surfaces at zero-K and ALD conditions.

\begin{tabular}{ccc}
\hline & $\mathrm{Co}(001)$ & $\mathrm{Co}(100)$ \\
& $(4 \times 4)$ & $(3 \times 3)$ \\
Zero-K condition & $0.67 \mathrm{ML} \mathrm{NH}+0.23 \mathrm{ML} \mathrm{NH}_{2}$ & $1 \mathrm{ML} \mathrm{NH}+1 \mathrm{ML} \mathrm{NH}_{2}$ \\
ALD condition & $0.56 \mathrm{ML} \mathrm{NH}$ & $0.67 \mathrm{ML} \mathrm{NH}+0.67 \mathrm{ML} \mathrm{NH}_{2}$ \\
\hline
\end{tabular}

At ALD operating condition (temperature range $550 \mathrm{~K}$ to $650 \mathrm{~K}$ ), some of the surface $\mathrm{NH}_{\mathrm{x}}$ species desorb from the surface. The preferred $\mathrm{NH}_{\mathrm{x}}$ coverages are ${ }^{31}$ : $\mathrm{Co}(001)$ surface is terminated with 0.56ML NH, which is $9 \mathrm{NH}$ in $(4 \times 4)$ supercell. On the $\mathrm{Co}(100)$ surface, the preferred surface termination is $0.67 \mathrm{ML} \mathrm{NH}$ and $0.67 \mathrm{ML} \mathrm{NH}_{2}$, which contains $6 \mathrm{NH}$ and $6 \mathrm{NH}_{2}$ in $(3 \times 3)$ supercell. The configurations of $\mathrm{NH}_{\mathrm{x}}$ terminations Co surfaces at the ALD operating condition are shown in Figure 1(c)-(d). On the (100) surface, due to the trench structure, NH prefers the subsurface 
channel bridge site and $\mathrm{NH}_{2}$ prefers the surface bridge site. The channel bridge is a bridge site with two channel metal atoms and the surface bridge is the bridge site with two surface metal atoms. The configuration of single $\mathrm{NH}$ and $\mathrm{NH}_{2}$ adsorbed on channel bridge and surface bridge sites is shown in Figure S1 in the supporting information.

(a)

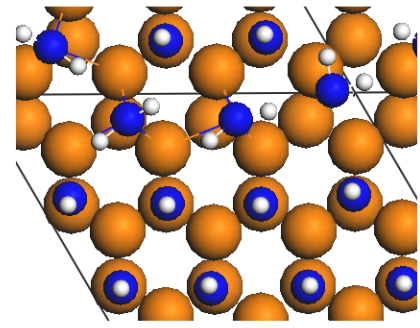

$0.67 \mathrm{ML} \mathrm{NH}+0.23 \mathrm{ML} \mathrm{NH}_{2}$ $\mathrm{Co}(001)$

(c)

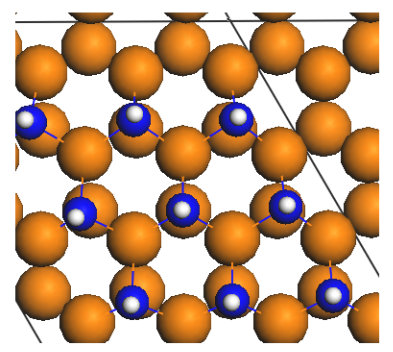

$0.56 \mathrm{MLNH} \mathrm{Co}(001)$ (b)

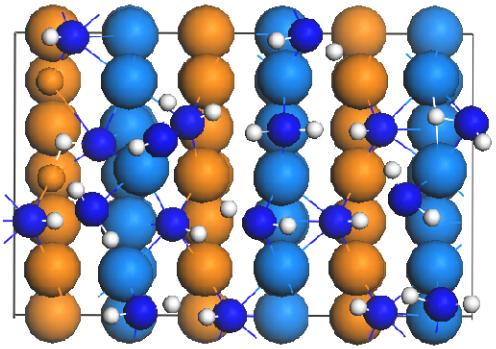

zero-K

condition

$1 \mathrm{ML} \mathrm{NH}+1 \mathrm{ML} \mathrm{NH}$

$\mathrm{Co}(100)$

(d)

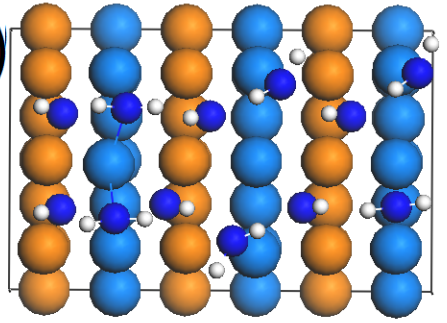

ALD operating

condition (550K-650K)
$0.67 \mathrm{ML} \mathrm{NH}+0.67 \mathrm{ML} \mathrm{NH}_{2}$ $\mathrm{Co}(100)$

Figure 1. The top view of $\mathrm{NH}_{\mathrm{x}}$ terminated metal surfaces at zero-K condition including (a) $\mathrm{Co}(001)$, and (b) $\mathrm{Co}(100)$ and at ALD operating condition including (c) $\mathrm{Co}(001)$, and (d) $\mathrm{Co}(100)$. Co atom is represented by orange for surface terminating atoms and light blue for the channel bridge subsurface atoms in the (100) surface; $\mathrm{N}$ atom and $\mathrm{H}$ atom are represented by dark blue and white atom, respectively. 
The molecular geometries of the metal precursor $\mathrm{CoCp}_{2}$ are relaxed in the same supercell as $\mathrm{Co}(001)$, with an energy cutoff of $400 \mathrm{eV}$ and Gamma point sampling. The van der Waals correction is applied with the PBE-D3 method to ensure an accurate description of the metal precursor adsorption energy. ${ }^{36}$ The activation barriers reported in this paper are computed using climbing image nudged elastic band (CI-NEB) method ${ }^{37}$ with 6 images including the starting and ending geometries and with the forces converged to $0.05 \mathrm{eV} / \AA$.

\section{Results and Discussions}

\subsection{Metal precursor adsorption on $\mathrm{NH}_{x}$-terminated $\mathrm{Co}(001)$ and (100) surfaces}

The structure of the gas phase metal precursor is first described. For $\mathrm{CoCp}_{2}$, the $\mathrm{Cp}-\mathrm{Cp}$ distance is between $3.39 \AA$ to $3.40 \AA$. The Co-C distance is between $2.08 \AA$ to $2.10 \AA$, indicating little tilting of the two Cp rings. When adsorbed on the $\mathrm{NH}_{\mathrm{x}}$-terminated metal surfaces, the metal precursor can be placed perpendicular to substrate with one $\mathrm{Cp}$ ring interacting with the surface (the upright position) or parallel to surface with both $\mathrm{Cp}$ rings interacting with the surface (the flat position). The adsorption energy is calculated from:

$$
E_{a d}=E_{t o t}-E_{\frac{N H x}{\text { Metal }}}-E_{A}
$$

where $\mathrm{E}_{\text {tot }}, \mathrm{E}_{\mathrm{NH} / \mathrm{Metal}}$, and $\mathrm{E}_{A}$ are the energy of the $\mathrm{NH}_{\mathrm{x}}$-terminated metal slab with adsorbed precursor $\mathrm{CoCp}_{2}$, the slab model for the $\mathrm{NH}_{\mathrm{x}}$-terminated metal surface, and the isolated $\mathrm{CoCp}_{2}$ precursor, respectively. All the energies are computed with the van der Waals correction included. A negative adsorption energy corresponds to exothermic adsorption. We will use the $\mathrm{NH}_{\mathrm{x}}$ coverages obtained at zero $\mathrm{K}$ and ALD conditions to explore the effect of $\mathrm{NH}_{\mathrm{x}}$ coverage on the $\mathrm{CoCp}_{2}$ pulse. 
3.1.1 Metal precursor adsorption on NHx-terminated Co (001) and (100) surfaces at high coverage

The calculated adsorption energies of the metal precursors on $\mathrm{NH}_{\mathrm{x}}$-terminated $\mathrm{Co}(001)$ and (100) surfaces at maximum $\mathrm{NH}_{\mathrm{x}}$ coverage (Table 1) are shown in Table 2. $\mathrm{Co}(001)$ is terminated with 0.67NL NH and 0.23ML $\mathrm{NH}_{2}$ and $\mathrm{Co}(100)$ has mixed termination with $1 \mathrm{ML} \mathrm{NH}$ and $1 \mathrm{ML} \mathrm{NH}_{2}$. On the (001) surface, the metal precursor prefers to bind to the substrate in the upright adsorption mode through one $\mathrm{Cp}$ ring. On the (100) surface, the metal precursor prefers to bind to the substrate through both $\mathrm{Cp}$ rings with the precursor in the flat configuration. These structures are shown in Figure 2(a)-(b). The configurations of the corresponding less stable adsorption structures are shown in Figure 2(c)-(d).

Table 2. The calculated adsorption energy of metal precursor $\mathrm{CoCp}_{2}$ adsorbed on $\mathrm{NH}_{\mathrm{x}}$-terminated $\mathrm{Co}(001)$ and (100) surfaces. The $\mathrm{NH} / \mathrm{NH}_{2}$ terminations correspond to the maximum $\mathrm{NH}_{\mathrm{x}}$ coverage.

\begin{tabular}{ccc}
\hline & $\operatorname{Co}(001)$ & $\operatorname{Co}(100)$ \\
\hline upright & -0.10 & -1.41 \\
flat & 3.16 & -1.73 \\
\hline
\end{tabular}

This difference in preferred binding mode at the two surface facets is due to the different surface structures. The (001) surface has a flat surface structure, while (100) surface has a unique zigzag structure. On the (001) surface, an upright position with one $\mathrm{Cp}$ ring close to metal surface results in stronger adsorption strength as this will maximise the number of interactions between the 
surface and carbon of the $\mathrm{Cp}$ ring. By contrast, the flat $\mathrm{CoCp}_{2}$ structure on (001) does not allow carbon-surface interactions and therefore the interaction is less favourable. In addition, in the upright binding mode, each carbon atom in the $\mathrm{Cp}$ ring is available for the hydrogen transfer step to form $\mathrm{CpH}$. On $\mathrm{Co}(001)$, the distances between the two $\mathrm{Cp}$ rings in the upright structure elongate to $3.43 \AA$, while the metal-C distances elongate to $2.11 \AA$ for the $\mathrm{Cp}$ ring interacting with the surface, which is a small elongation compared to the free precursor.

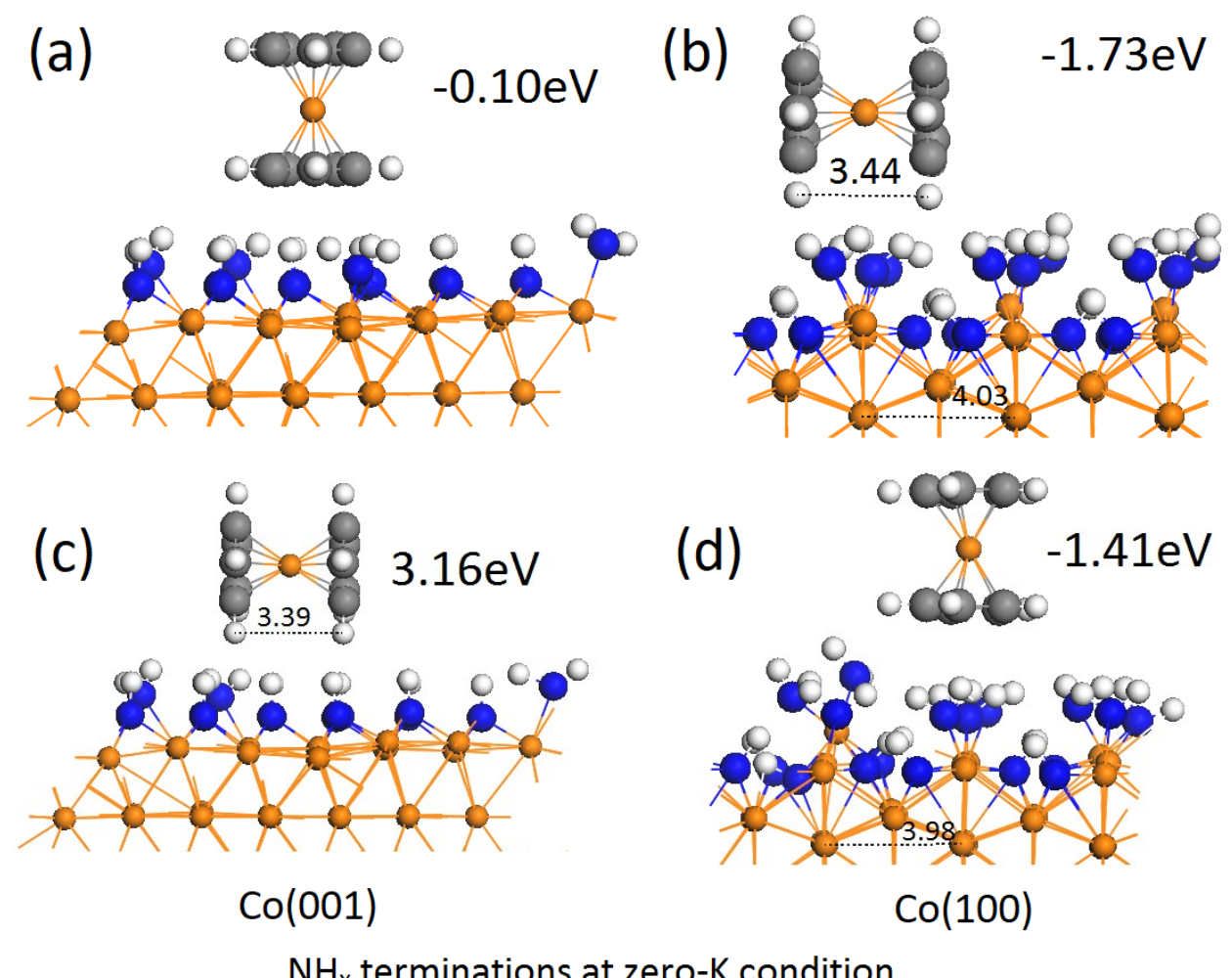

Figure 2. The configurations of the most stable adsorption of precursor $\mathrm{CoCp}_{2}$ on (a) $\mathrm{Co}(001)$ surface, and (b) $\mathrm{Co}(100)$ surface and the less stable adsorption pf precursor $\mathrm{CoCp}_{2}$ on (c) $\operatorname{Co}(001)$ surface, and (d) $\mathrm{Co}(100)$ surface. The $\mathrm{NH}_{\mathrm{x}}$ termination is with respect to zero-K condition. Co atoms are represented by orange spheres; Carbon, nitrogen and hydrogen atoms are represented by grey, blue and white colour, respectively. 
On the Co (100) surface, the distance across the trench (between two neighbouring surface metal atoms) is $4.03 \AA$. The distances between the two Cp rings in flat configuration are in the range of $3.34 \AA$ to $3.44 \AA$ and the metal-C distances are $2.07 \AA$ to $2.10 \AA$. The metal precursor can therefore be well-accommodated within the trench structure of the $\operatorname{Co}(100)$ surface, which promotes the adsorption of the precursor, as indicated by the computed adsorption energies. Compared to free metal $\mathrm{Cp}$ precursors, the two $\mathrm{Cp}$ rings are tilted with shorter ring-ring distance for the atoms away from the surface and longer ring-ring distance for the atoms closer to the surface.

3.1.2 Metal precursor adsorption on NHx-terminated Co (001) and (100) surfaces at low $\mathrm{NH}_{x}$ coverage, corresponding to the ALD operating condition

The calculated adsorption energies of the metal precursors on the $\mathrm{NH}_{\mathrm{x}}$-terminated $\mathrm{Co}(001)$ and (100) surfaces corresponding to the lower $\mathrm{NH}_{\mathrm{x}}$ coverage and the ALD operating condition are shown in Table 3. The initial $\mathrm{NH}_{\mathrm{x}}$ terminations are now $0.56 \mathrm{ML} \mathrm{NH}$ on $\mathrm{Co}(001)$ and the mixed termination with $0.67 \mathrm{ML} \mathrm{NH}$ and $0.67 \mathrm{ML} \mathrm{NH}_{2}$ on $\mathrm{Co}(100)$. 
Table 3. The calculated adsorption energy of metal precursor $\mathrm{RuCp}_{2}$ and $\mathrm{CoCp}_{2}$ adsorbed on (001) and (100) surfaces. The $\mathrm{NH} / \mathrm{NH}_{2}$ terminations corresponds to ALD operating condition (temperature range $550 \mathrm{~K}-650 \mathrm{~K}$ ).

\begin{tabular}{ccc}
\hline & $\mathrm{Co}(001)$ & $\mathrm{Co}(100)$ \\
\hline upright & -0.68 & -0.34 \\
flat & -0.56 & -1.67 \\
\hline
\end{tabular}

The binding preference of $\mathrm{CoCp} 2$ is the same as the higher $\mathrm{NH}_{\mathrm{x}}$ coverage surfaces and the relaxed adsorption structures are shown in Figure 3(a)-(b). The configurations of less stable adsorption structures are shown in Figure 3(c)-(d). On Co(001) surface, an upright position with one Cp ring close to metal surface can result in stronger adsorption strength, although the flat adsorption mode is now much more favourable compared to the same adsorption mode at higher $\mathrm{NH}_{\mathrm{x}}$ coverage. The distances between the two $\mathrm{Cp}$ rings are in the range of $3.37 \AA$ to $3.40 \AA$ on $\operatorname{Co}(001)$ surface. Compared with free $\mathrm{CoCp}_{2}$, the two $\mathrm{Cp}$ rings are slightly tilted. The distances for metal-C are between $2.08 \AA$ and $2.10 \AA$. 

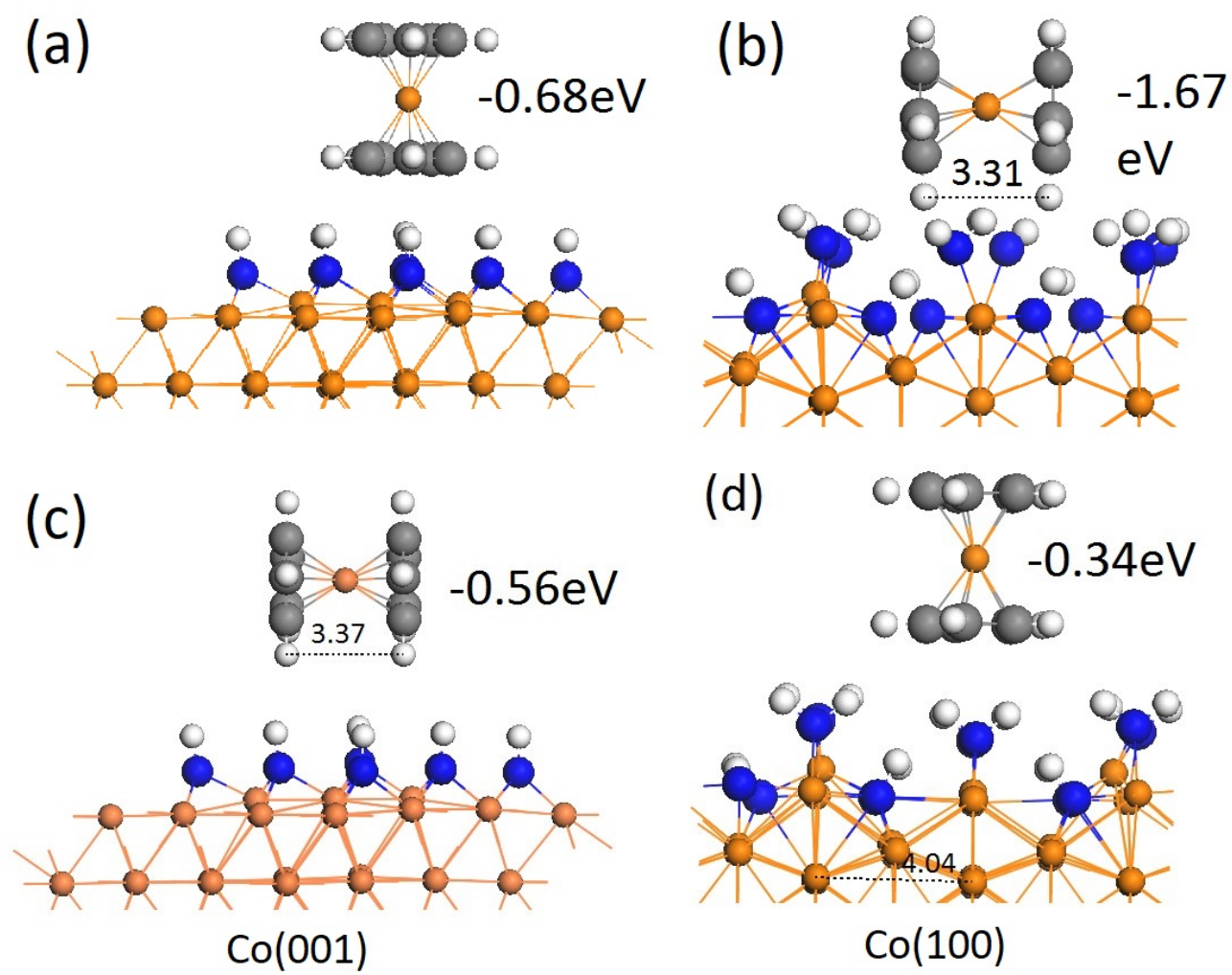

Co(001)

$\mathrm{Co}(100)$

$\mathrm{NH}_{\mathrm{x}}$ termination at ALD operating condition

Figure 3. The configurations of the most stable adsorption of precursor $\mathrm{CoCp}_{2}$ on (a) $\mathrm{Co}(001)$ surface, and (b) $\operatorname{Co}(100)$ surface and the less stable adsorption pf precursor $\mathrm{CoCp}_{2}$ on (c) $\operatorname{Co}(001)$ surface, and (d) $\mathrm{Co}(100)$ surface. The $\mathrm{NH}_{\mathrm{x}}$ termination is with respect to ALD operating condition. Co atoms are represented by orange spheres; Carbon, nitrogen and hydrogen atoms are represented by grey, blue and white colour, respectively.

The distance across the trench between two neighbouring metal atoms is $4.03 \AA$ on $\operatorname{Co}(100)$ surface. The distances between the two Cp rings are in the range of $3.31 \AA$ to $3.40 \AA$. The distances for metal-C are $2.06 \AA$ to $2.10 \AA$. The flat adsorption mode of metal precursor can be wellaccommodated within the trench of the (100) surfaces, which can result in stronger adsorption strength. Compared to free metal $\mathrm{Cp}$ precursors, the two $\mathrm{Cp}$ rings are tilted with shorter ring-ring 
distances for the atoms closer to the surface and longer ring-ring distances for the atoms away from the surface.

\subsection{Single precursor reaction pathway on Co (001) and (100) surfaces with $\mathrm{NH}_{x}$ terminations at ALD operating condition}

The reaction pathway during the metal precursor pulse is studied with respect to the $\mathrm{NH}_{\mathrm{x}}$ terminations at ALD operating condition. In this section, we address the reaction mechanism when a single $\mathrm{CoCp}_{2}$ precursor is adsorbed on $\mathrm{NH}_{\mathrm{x}}$-terminated $\mathrm{Co}(001)$ and (100) surfaces. Once the metal precursor is adsorbed on $\mathrm{NH}_{\mathrm{x}}$-terminated metal surfaces, the $\mathrm{Cp}$ ligand can undergo hydrogen transfer, $\mathrm{CpH}$ formation, $\mathrm{CpH}$ desorption, second hydrogen transfer, and second $\mathrm{CpH}$ formation and desorption.

Upon adsorption, no spontaneous hydrogen transfer was observed on any $\mathrm{NH}_{\mathrm{x}}$-terminated Co (001) and (100) surfaces. This means that the hydrogen transfer step must overcome an activation barrier. The possible reactions of a single adsorbed molecule of $\mathrm{CoCp}_{2}$ on $\mathrm{NH}_{\mathrm{x}}$ terminated metal surfaces can be illustrated as follows:

$$
\begin{gathered}
A: H^{*}+\operatorname{CoCp}_{2} \rightarrow \operatorname{CoC} p^{*}+H C p \\
B: H^{*}+\operatorname{CoC} p \rightarrow C o^{*}+H C p
\end{gathered}
$$

where reaction $\mathrm{A}$ involves the first $\mathrm{Cp}$ ligand and reaction $\mathrm{B}$ involves the second $\mathrm{Cp}$ ligand. We have calculated the energy along the reaction pathway and the activation barriers for hydrogen transfer at each step. Note that the reaction energies of precursor adsorption $\left(\mathrm{E}_{\text {adsorption }}\right)$ and the first

hydrogen transfer $\left(\mathrm{E}_{\text {hydrogen }}{ }^{\mathrm{I}}\right)$ are with reference to the $\mathrm{NH}_{\mathrm{x}}$-terminated metal surface and free 
$\mathrm{CoCp}_{2}$. If one $\mathrm{CpH}$ molecule desorbs from the surface, the reaction energies of first $\mathrm{CpH}$ desorption $\left(\mathrm{E}^{\text {Des }}{ }_{\mathrm{CpH}} \mathrm{I}\right)$, second hydrogen transfer $\left(\mathrm{E}_{\text {hydrogen }}{ }^{\mathrm{II}}\right)$, and second $\mathrm{CpH}$ desorption $\left(\mathrm{E}^{\mathrm{Des}} \mathrm{CpH}^{\mathrm{II}}\right)$ are with reference to $\mathrm{NH}_{\mathrm{x}}$-terminated metal surface with adsorbed $\mathrm{CoCp}_{2}$, and free $\mathrm{CpH}$.

The results for $\mathrm{NH}_{\mathrm{x}}$ terminations at $\mathrm{ALD}$ operating condition are summarized in Figure 4 and the calculated barriers for the hydrogen transfer steps are presented in Table 4. In order to assess any role of $\mathrm{NH} / \mathrm{NH}_{2}$ coverage, the results for $\mathrm{NH}_{\mathrm{x}}$ terminations at highest coverage, i.e. zero $\mathrm{K}$, are summarized in Figure S2 and the calculated barrier for the hydrogen transfer steps are presented in Table S1 in supporting information.

Table 4. The calculated reaction energy for hydrogen transfer step and reaction barriers, Ebarrier, on Co (001) and (100) surfaces with $\mathrm{NH}_{\mathrm{x}}$ terminations corresponding to ALD operating condition. $\mathrm{E}_{\text {adsorption }}$ is the energy change upon precursor adsorption, $\mathrm{E}_{\text {hydrogen }}{ }^{\mathrm{I}}$ and $\mathrm{E}_{\text {hydrogen }}{ }^{\mathrm{II}}$ are the energy change for the first and second hydrogen transfer, and $\mathrm{E}^{\mathrm{Des}} \mathrm{CpH}^{\mathrm{I}}$ is the desorption energy of $\mathrm{CpH}$.

\begin{tabular}{cccc|ccc}
\hline \multicolumn{3}{c|}{$H^{*}+\mathrm{CoCp}_{2} \rightarrow \mathrm{CoCp}{ }^{*}+\mathrm{HCp}$} & \multicolumn{3}{|c}{$H^{*}+\mathrm{CoCp} \rightarrow \mathrm{Co}^{*}+\mathrm{HCp}$} \\
\hline & Eadsorption & $\mathrm{E}_{\text {hydrogen }}{ }^{\mathrm{I}}$ & $\mathrm{E}_{\text {barrier }}$ & $\mathrm{E}^{\mathrm{Des}} \mathrm{CpH}^{\mathrm{I}}$ & $\mathrm{E}_{\text {hydrogen }}{ }^{\mathrm{II}}$ & $\mathrm{E}_{\text {barrier }}$ \\
\hline $\mathrm{Co}(001)$ & -0.68 & -0.63 & 0.56 & -1.69 & -0.72 & 1.57 \\
$\mathrm{Co}(100)$ & -1.67 & -2.19 & 0.52 & -1.32 & -1.15 & 0.85 \\
\hline
\end{tabular}



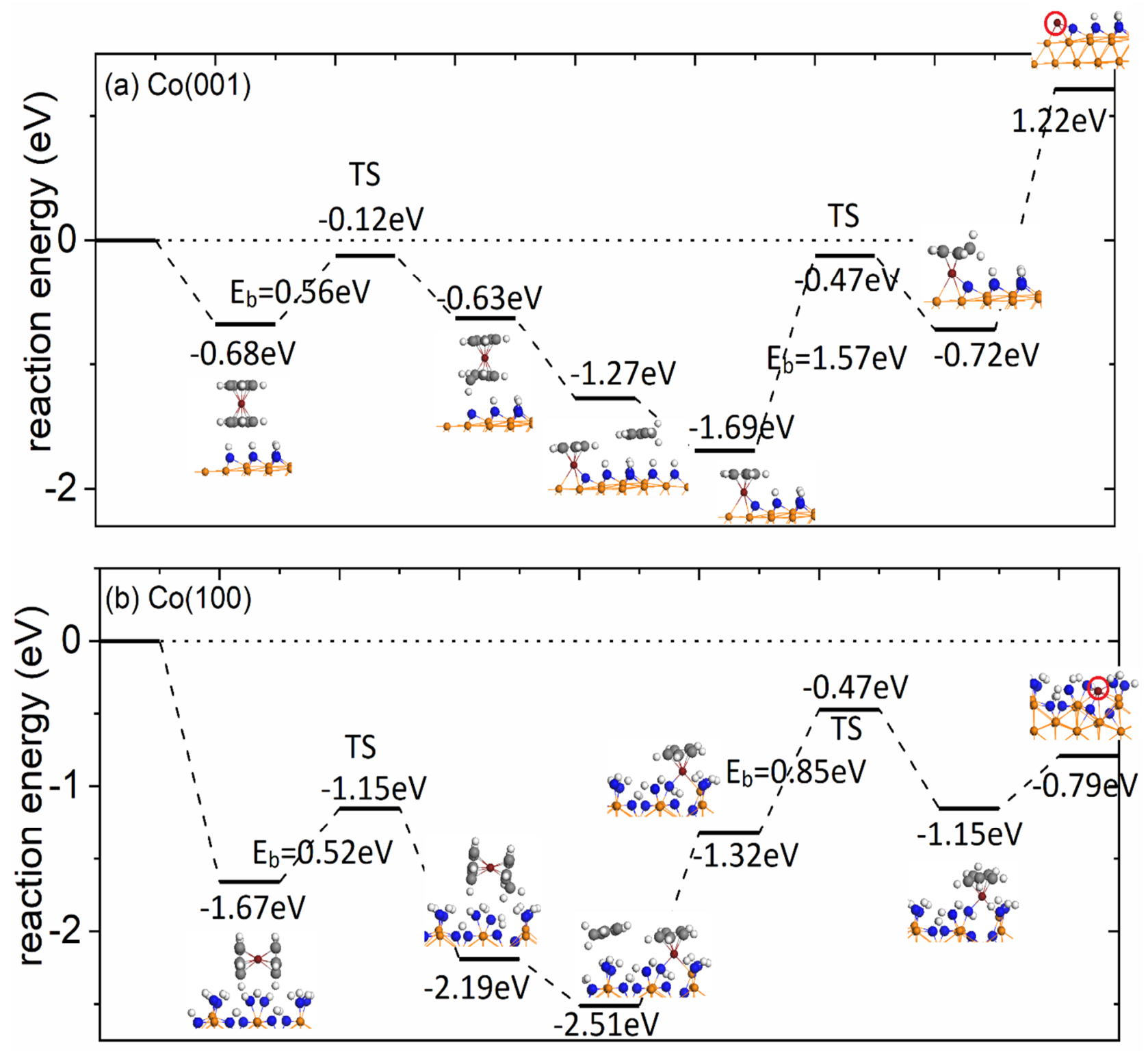

$\mathrm{NH}_{\mathrm{x}}$ terminations at ALD operating condition

Figure 4. The plotted metal precursor reaction pathway on (a) $\operatorname{Co}(001)$ surface and (b) $\operatorname{Co}(100)$ surface with $\mathrm{NH}_{\mathrm{x}}$ terminations at ALD operating condition. The $\mathrm{Cp}$ ligand is eliminated via hydrogen transfer. The substrate Co atoms are represented by orange spheres and the Co atom from $\mathrm{CoCp}_{2}$ is represented by a red colour. Carbon, nitrogen and hydrogen atoms are represented by grey, blue and white colour, respectively. 
On the $\mathrm{Co}(001)$ surface, the metal precursor $\mathrm{CoCp}_{2}$ has a moderate adsorption strength ( $\mathrm{E}_{\text {adsorption }}$ $=-0.68 \mathrm{eV})$. The first $\mathrm{Cp}$ ligand elimination via hydrogen transfer is thermoneutral with a moderate barrier of $0.56 \mathrm{eV}$ for transfer of hydrogen and a small energy change of $0.05 \mathrm{eV}$. The formation and desorption of this $\mathrm{CpH}$ are exothermic and the elimination of this $\mathrm{CpH}$ makes the reaction exothermic with a total energy gain of $-1.69 \mathrm{eV}$.

Considering now the elimination of the second $\mathrm{Cp}$ ligand via hydrogen transfer is highly endothermic with a high activation barrier for hydrogen transfer, which is $1.57 \mathrm{eV}$. The desorption of the second $\mathrm{CpH}$ to give a bare $\mathrm{Co}$ species that is bound to surface $\mathrm{N}$ atom is thermodynamically unfavourable. Thus, the final termination is a CoCp termination on $\mathrm{Co}(001)$ as a result of the high barrier and endothermic reaction for the elimination of the second $\mathrm{Cp}$ ligand.

At the highest $\mathrm{NH}_{\mathrm{x}}$ coverage, the terminations on $\mathrm{Co}(001)$ are $0.67 \mathrm{ML} \mathrm{NH}$ and $0.23 \mathrm{ML} \mathrm{NH}_{2}$. As shown on Figure S2(a) in supporting information, the overall reactions for Cp ligand eliminations via hydrogen transfer step are exothermic. The calculated barriers are $1.00 \mathrm{eV}$ and $1.24 \mathrm{eV}$ for first and second hydrogen transfer steps. However, the initial adsorption of metal precursor $\mathrm{CoCp}_{2}$ is quite weak, which has the value of $-0.10 \mathrm{eV}$, so that this reaction is not likely to proceed.

On the $\mathrm{Co}(100)$ surface, we find that for the hydrogen transfer step, the channel $\mathrm{H}$ atom is more reactive than the surface $\mathrm{H}$ atom. Table 5 compares the energies for transfer of these two hydrogen species. On the $\operatorname{Co}(100)$ surface, after relaxation, a channel hydrogen atom migrates to the surface $\mathrm{N}$ atom that has lost hydrogen and this recovers to form $\mathrm{NH}_{2}$. Thus, in the subsequent discussion of hydrogen transfer on the $\operatorname{Co}(100)$ surfaces, the channel $\mathrm{H}$ is the active species for hydrogen transfer to the Cp ligand. 
Table 5. The calculated reaction energy for hydrogen transfer step from surface $\mathrm{H}$ and channel $\mathrm{H}$ on $\mathrm{Co}(100)$ surface. The results for transfer of different $\mathrm{H}$ species show that channel $\mathrm{H}$ is more reactive than surface $\mathrm{H}$ on the $\mathrm{Co}(100)$ surface.

\begin{tabular}{ccc}
\hline & High $\mathrm{NH}_{\mathrm{x}}$ Coverage & ALD Coverage \\
\hline Adsorption & $\mathrm{Co}(100) / \mathrm{eV}$ & $\mathrm{Co}(100) / \mathrm{eV}$ \\
$\begin{array}{c}\text { hydrogen transfer } \\
\text { channel } \mathrm{H}\end{array}$ & -1.73 & -1.67 \\
$\begin{array}{c}\text { hydrogen transfer } \\
\text { surface } \mathrm{H}\end{array}$ & -3.12 & -2.19 \\
\hline
\end{tabular}

The reaction pathway on $\operatorname{Co}(100)$ surface is shown in Figure 4(b). The reaction energies for all steps are exothermic, so that the loss of two $\mathrm{Cp}$ ligands as $\mathrm{CpH}$ via hydrogen is overall exothermic by $-0.79 \mathrm{eV}$. The $\mathrm{CoCp}_{2}$ precursor initially adsorbs on the $\mathrm{NH}_{\mathrm{x}}$ terminated $\mathrm{Co}(100)$ surface with a gain of $-1.67 \mathrm{eV}$. The first hydrogen transfer step is exothermic, with a moderate activation barrier of $0.52 \mathrm{eV}$ and a gain of $-0.52 \mathrm{eV}$ in energy. After the first $\mathrm{Cp}$ ligand desorption, the second hydrogen transfer step is practically thermoneutral with a moderate barrier of $0.85 \mathrm{eV}$ and a small energy cost of $0.17 \mathrm{eV}$. Finally, the desorption of the second $\mathrm{CpH}$ shows an energy gain of $-0.79 \mathrm{eV}$ and the resulting surface structure shows a Co atom which binds to a nitrogen atom from which a $\mathrm{H}$ atom transferred to $\mathrm{Cp}$.

At the highest $\mathrm{NH}_{\mathrm{x}}$ coverage, the terminations on $\mathrm{Co}(100)$ are $1 \mathrm{ML} \mathrm{NH}$ and $1 \mathrm{ML} \mathrm{NH}_{2}$. As shown on Figure S2(b) in supporting information, the overall reaction for Cp ligand eliminations via hydrogen transfer step is exothermic. The calculated barriers for the first and second hydrogen 
transfer steps are $1.56 \mathrm{eV}$ and $0.84 \mathrm{eV}$. However, the first $\mathrm{CpH}$ formation is endothermic with a high energy cost of $2.82 \mathrm{eV}$. This is due to very strong adsorption of $\mathrm{CoCp}_{2} \mathrm{H}$ on the $\mathrm{Co}(100)$ surface after the hydrogen transfer step, which had an energy gain of $-3.12 \mathrm{eV}$. Thus, with the highest $\mathrm{NH}_{\mathrm{x}}$ coverage, the precursor is too strongly bound to the substrate.

To summarize, for $\mathrm{NH}_{\mathrm{x}}$ terminations of $\mathrm{Co}(001)$ and (100) at typical ALD operating conditions, at least one Cp ligand can be eliminated via a hydrogen transfer step. On the $\operatorname{Co}(001)$ surface, the activation barriers are $0.56 \mathrm{eV}$ and $1.57 \mathrm{eV}$ for the first and second hydrogen transfer steps. Due to high barrier and endothermic reaction, the elimination of second $\mathrm{Cp}$ ligand is unfavourable and the termination for a single $\mathrm{Co}(\mathrm{Cp})_{2}$ precursor is a $\mathrm{CoCp}$ fragment on $\mathrm{NH}_{\mathrm{x}}$ terminated $\mathrm{Co}(001)$ surface. On the $\mathrm{Co}(100)$ surface, the activation barriers for the first and second hydrogen transfer steps are $0.52 \mathrm{eV}$ and $0.85 \mathrm{eV}$, which would be easily overcome at typical ALD conditions. The two Cp ligands are eliminated and the final desorption of $\mathrm{CpH}$ shows an energy gain of $-0.79 \mathrm{eV}$. The resulting surface termination after reaction of a single precursor is a Co atom deposited on $\mathrm{NH}_{\mathrm{x}}$ terminated $\operatorname{Co}(100)$ surface, which binds to surface $\mathrm{N}$ atom. The distance between the deposited Co atom and nearest $\mathrm{N}$ atom is $1.84 \square$. These structures are shown in Figure 5 . Not only the $\mathrm{NH}_{\mathrm{x}}$ coverage, but also the surface facet play a crucial role in the adsorption strength of the precursor and the energetics of the hydrogen transfer and $\mathrm{CpH}$ formation and removal steps. 
(a)

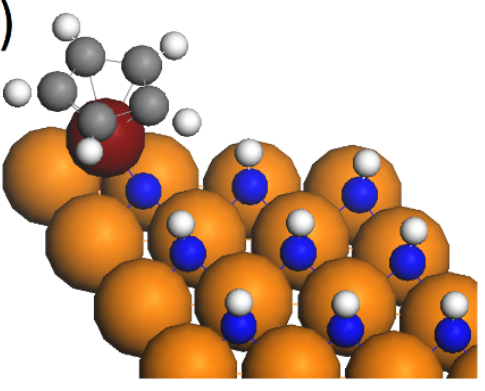

Co(001) (b)

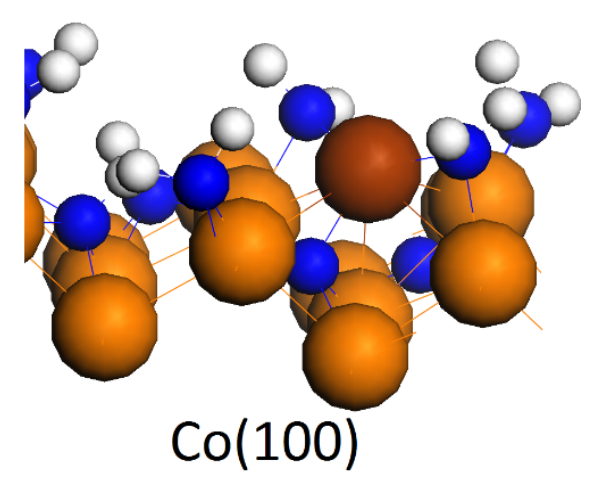

$\mathrm{NH}_{\mathrm{x}}$ terminations at ALD operating condition

Figure 5. The configurations of the final structures after single metal precursor $\mathrm{CoCp}_{2}$ adsorption and ligand elimination on the (a) $\mathrm{Co}(001)$ and (b) $\mathrm{Co}(100)$ surface. $\mathrm{The}^{\mathrm{N}} \mathrm{H}_{\mathrm{x}}$ terminations are at ALD operating condition. The substrate Co atom is represented by orange colour and the Co atom from metal precursor $\mathrm{CoCp}_{2}$ is represented by wine red colour. Carbon, nitrogen and hydrogen atoms are represented by grey, blue and white colour, respectively.

3.3 Precursor coverage effect on the reaction mechanism on Co (001) and (100) surfaces with $\mathrm{NH}_{x}$ terminations at ALD operating condition

We now address the adsorption and further reaction of two $\operatorname{Co}(\mathrm{Cp})_{2}$ precursors. The adsorption energy is calculated from:

$$
E_{a d}=E_{\text {tot }}-E_{\frac{N H x}{\text { Metal }}}-2 * E_{A}
$$

where $\mathrm{E}_{\mathrm{tot}}, \mathrm{E}_{\mathrm{NH} / \mathrm{Metal}}$, and $\mathrm{E}_{A}$ are the energy of the $\mathrm{NH}_{\mathrm{x}}$-terminated metal slab with two precursor $\mathrm{CoCp} 2$, the slab model for the $\mathrm{NH}_{\mathrm{x}}$-terminated metal surface, and isolated precursor $\mathrm{CoCp}_{2}$, respectively. Dividing the computed energy by two gives the adsorption energy per precursor. All energies are computed with the inclusion of the van der Waals corrections. The adsorption 
structures of two precursors on Co (001) and (100) surfaces at the ALD coverage of $\mathrm{NH}_{\mathrm{x}}$ are shown in Figure 6.
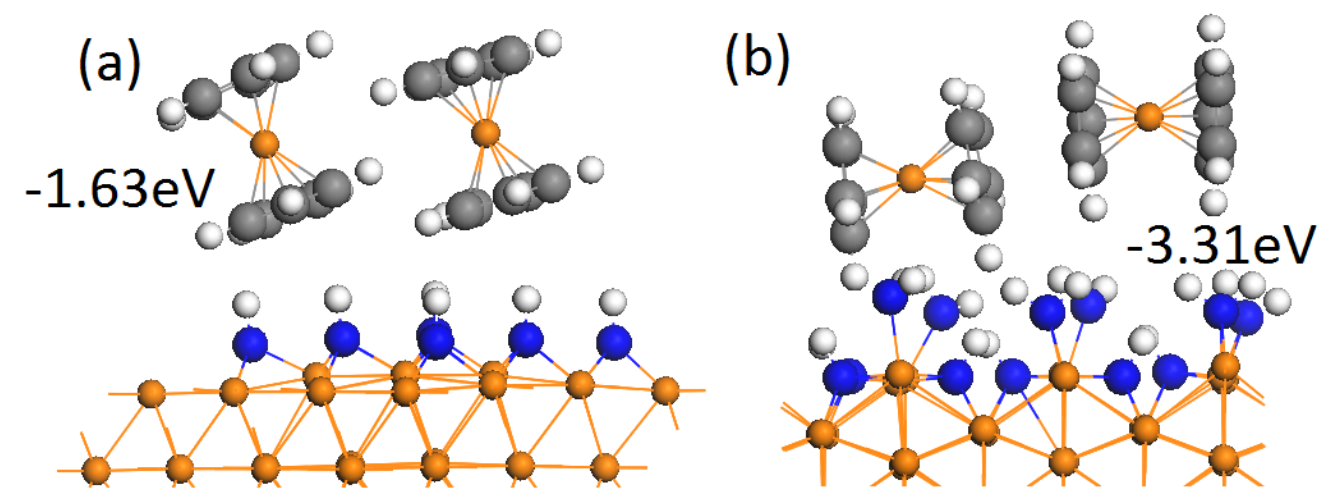

Figure 6. The configurations of two precursor $\mathrm{CoCp}_{2}$ on $\mathrm{NHx}$-terminated (a) $\mathrm{Co}(001)$ surface, and (b) $\mathrm{Co}(100)$. The substrate Co atom is represented by orange. Carbon, nitrogen and hydrogen atoms are represented by grey, blue and white colour, respectively.

The preferred binding mode for two precursors is the same as for adsorption of a single precursor. On the $\operatorname{Co}(001)$ surface, the upright adsorption mode is the most stable, while on the (100) surface the flat adsorption mode is the most stable. These adsorption modes are exothermic with computed adsorption energies of $-1.63 \mathrm{eV}$ and $-3.31 \mathrm{eV}$, giving adsorption energies per precursor are $-0.81 \mathrm{eV}$ and $-1.65 \mathrm{eV}$. Thus on the (001) surface, precursor adsorption is enhanced compared with adsorption of a single precursor $(-0.68 \mathrm{eV})$. In this adsorption configuration we see tilting of the two $\mathrm{CoCp}_{2}$ precursors. Compared with adsorption of a single $\mathrm{CoCp}_{2}$ on the $\mathrm{Co}(100)$ surface, there is no difference in adsorption energy per precursor.

The further reaction of two precursor molecules of $\mathrm{CoCp}_{2}$ on the $\mathrm{NH}_{\mathrm{x}}$ terminated metal surfaces at ALD operating condition can proceed as follows: 


$$
\begin{aligned}
& C: H^{*}+\mathrm{CoCp}_{2}+\mathrm{CoCp} p_{2} \rightarrow \mathrm{CoCp} p_{2}+\mathrm{CoCp} p^{*}+\mathrm{HCp} \\
& \text { D1: } \mathrm{H}^{*}+\mathrm{CoCp}_{2}+\mathrm{CoCp}^{*} \rightarrow \mathrm{CoCp}_{2}+\mathrm{Co}^{*}+\mathrm{HCp} \\
& \text { D2: } \mathrm{H}^{*}+\mathrm{CoCp}_{2}+\mathrm{CoCp}^{*} \rightarrow \mathrm{CoCp}^{*}+\mathrm{CoCp}^{*}+\mathrm{HCp}
\end{aligned}
$$

Here, after the first hydrogen transfer, Reaction C, the second hydrogen transfer can result in two different by-products. Reaction $\mathrm{D} 1$ results in a $\mathrm{Co}$ atom and an intact adsorbed $\mathrm{CoCp}_{2}$, while in reaction D2, two adsorbed CoCp fragments are present on the surface. The reaction energies of two precursor adsorption are with reference to the $\mathrm{NH}_{\mathrm{x}}$-terminated metal surface and two free $\mathrm{CoCp}_{2}$. If one $\mathrm{CpH}$ molecule desorbs from the surface, the reaction energies are with reference to $\mathrm{NH}_{\mathrm{x}}$-terminated metal surface, two free $\mathrm{CoCp}_{2}$, and free $\mathrm{CpH}$. The reaction pathways are shown in Figure 7, with Reactions D1 and D2 shown in different colours and the calculated barriers for each hydrogen transfer step are presented in Table 6.

Table 6. The computed energy barriers for hydrogen transfer steps with respect to two metal precursors adsorption on $\mathrm{NH}_{\mathrm{x}}$ terminated $\mathrm{Co}(001)$ and (100) surfaces at ALD conditions.

\section{Computed Barriers/eV}

$$
\begin{array}{ccc}
C: H^{*}+\mathrm{CoCp}_{2}+\mathrm{CoCp}_{2} \rightarrow & \mathrm{D} 1: \mathrm{H}^{*}+\mathrm{CoCp}_{2}+\mathrm{CoCp}^{*} \rightarrow & D 2: \mathrm{H}^{*}+\mathrm{CoCp}_{2}+\mathrm{CoCp}^{*} \rightarrow \\
\mathrm{CoCp} p_{2}+\mathrm{CoCp}^{*}+\mathrm{HCp} & \mathrm{CoCp} p_{2}+\mathrm{Co}^{*}+\mathrm{HCp} & \mathrm{CoCp} p^{*}+\mathrm{CoCp}^{*}+\mathrm{HCp}
\end{array}
$$

\begin{tabular}{lccc}
\hline $\operatorname{Co}(001)$ & 0.74 & 1.18 & 0.75 \\
$\operatorname{Co}(100)$ & No barrier & 0.79 & 1.78
\end{tabular}



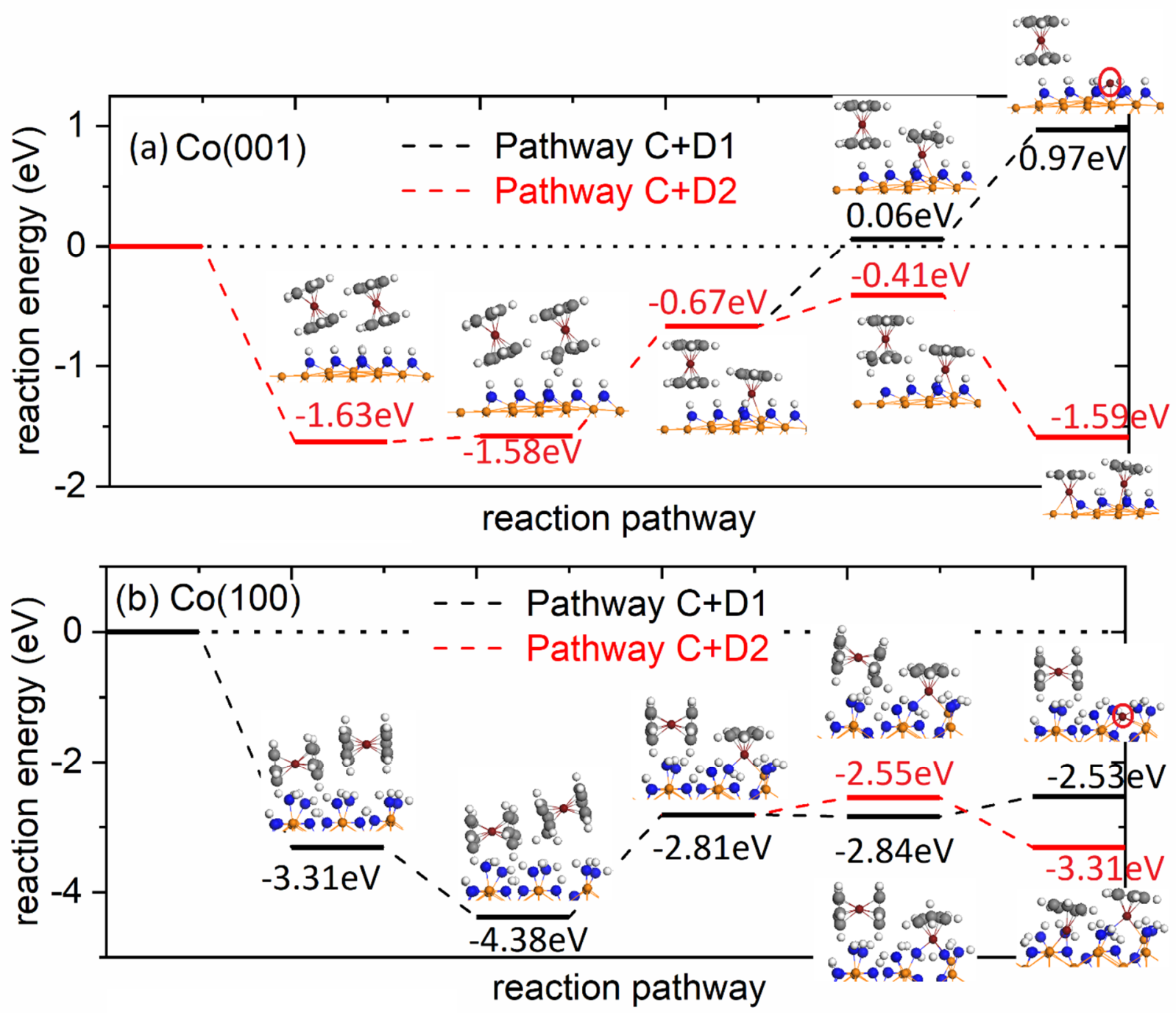

Figure 7. The $\mathrm{CoCp}_{2}$ precursor reaction pathway on (a) $\mathrm{Co}(001)$ surface and (b) $\mathrm{Co}(100)$ surface for two CoCp 2 precursors. The black pathway is for reaction D1, resulting in a Co atom and adsorbed $\mathrm{CoCp}_{2}$. The red pathway is for reaction D2, resulting in two CoCp fragments at the surface. The substrate Co atom is represented by orange colour and the Co atom from metal precursor $\mathrm{CoCp}_{2}$ is represented by wine red colour. Carbon, nitrogen and hydrogen atoms are represented by grey, blue and white colour, respectively. 
On the $\operatorname{Co}(001)$ surface, the first hydrogen transfer step is thermoneutral with a small energy change of $0.05 \mathrm{eV}$ and a moderate activation barrier of $0.74 \mathrm{eV}$. This barrier is larger by $0.18 \mathrm{eV}$ compared to the barrier for the first hydrogen transfer for a single $\mathrm{CoCp}_{2}$ precursor. This indicates that a neighbouring precursor might slightly hinder the reactivity on the Co(001) surface.

After the desorption of $\mathrm{fCpH}$, the elimination of the second $\mathrm{Cp}$ ligand for the same precursor, reaction D1, is unfavourable with an endothermic reaction energy and a high activation barrier of $1.18 \mathrm{eV}$. The trend that formation of a bare Co atom is unfavourable on this surface persists with two $\mathrm{CoCp}_{2}$ precursors.

Alternatively, following reaction $\mathrm{D} 2$, the intact $\mathrm{CoCp}_{2}$ precursor undergoes hydrogen transfer from the surface, with a moderate activation barrier of $0.75 \mathrm{eV}$, which is similar to that of reaction $\mathrm{C}$. The elimination of the second $\mathrm{Cp}$ ligand is not favoured. Thus, with adsorption of multiple precursors, the final termination remains $\mathrm{CoCp}$ fragments on $\mathrm{Co}(001)$ surface.

On the $\operatorname{Co}(100)$ surface, the adsorption of two metal precursors is exothermic with a large energy gain of $-3.31 \mathrm{eV}$. As previously described, the channel $\mathrm{H}$ atom is more reactive than surface $\mathrm{H}$ atom. The first hydrogen transfer of the channel $\mathrm{H}$ atom is exothermic and is barrierless. Thus, a neighbouring $\mathrm{CoCp}_{2}$ precursor promotes the first hydrogen transfer step by reducing the activation barrier from $0.52 \mathrm{eV}$ to no barrier on $\mathrm{Co}(100)$ surface.

After the desorption of this $\mathrm{CpH}$, the elimination of the second $\mathrm{Cp}$ ligand from the same precursor as reaction $\mathrm{C}$, indicated as reaction $\mathrm{D} 1$, with a computed activation barrier of $0.79 \mathrm{eV}$, has a much lower activation barrier than the hydrogen transfer to a $\mathrm{Cp}$ ligand of the neighbouring $\mathrm{CoCp}_{2}$ precursor, denoted as reaction $\mathrm{D} 2$, which has an activation barrier of $1.78 \mathrm{eV}$. Thus, the elimination of two Cp ligands from one precursor is favoured rather than elimination from each precursor and 
after two hydrogen transfer steps, the resulting structure is one Co atom deposited on the surface binding to $\mathrm{N}$ atom, and one intact $\mathrm{CoCp}_{2}$ molecule.

After the elimination of two $\mathrm{Cp}$ ligands from a $\mathrm{CoCp}_{2}$ precursor, we then further investigate hydrogen transfer and $\mathrm{Cp}$ elimination for the second $\mathrm{CoCp}_{2}$ precursor, with the deposited Co on the $\operatorname{Co}(100)$ surface. The reactions are illustrated as follows:

$$
\begin{gathered}
E: H^{*}+\mathrm{CoCp}_{2}+\mathrm{Co}^{*} \rightarrow \mathrm{CoC} p^{*}+\mathrm{Co}^{*}+\mathrm{HCp} \\
F: H^{*}+\mathrm{CoC} p^{*}+\mathrm{Co}^{*} \rightarrow \mathrm{Co}^{*}+\mathrm{Co}^{*}+H C p
\end{gathered}
$$

The results are summarized in Figure 8. Again, the channel $\mathrm{H}$ atom is more reactive than the surface $\mathrm{H}$ atom. The first hydrogen transfer step is slightly endothermic, but still highly exothermic overall, with a moderate activation barrier of $0.89 \mathrm{eV}$. After the desorption of first $\mathrm{CpH}$, the second hydrogen transfer step is exothermic and has a moderate barrier of $0.75 \mathrm{eV}$. After the second $\mathrm{CpH}$ desorption, two Co atoms are deposited on the surface.

The computed activation barriers for $\mathrm{H}$ transfer for a single $\mathrm{CoCp}_{2}$ precursor, two surface bound $\mathrm{CoCp}_{2}$ species, and one precursor with a bare $\mathrm{Co}$ atom $\mathrm{Co}+\mathrm{CoCp} \mathrm{p}_{2}$ on $\mathrm{Co}(100)$ surface are summarized in Table 7. We see that the activation barriers for Cp elimination via hydrogen transfer steps are all moderate and can be overcome at ALD operating condition and on this surface $\mathrm{CpH}$ elimination proceeds to leave Co atoms on the $\operatorname{Co}(100)$ surface. These Co atoms are bound to nitrogen atoms with Co-N distances of XXXXXX. 


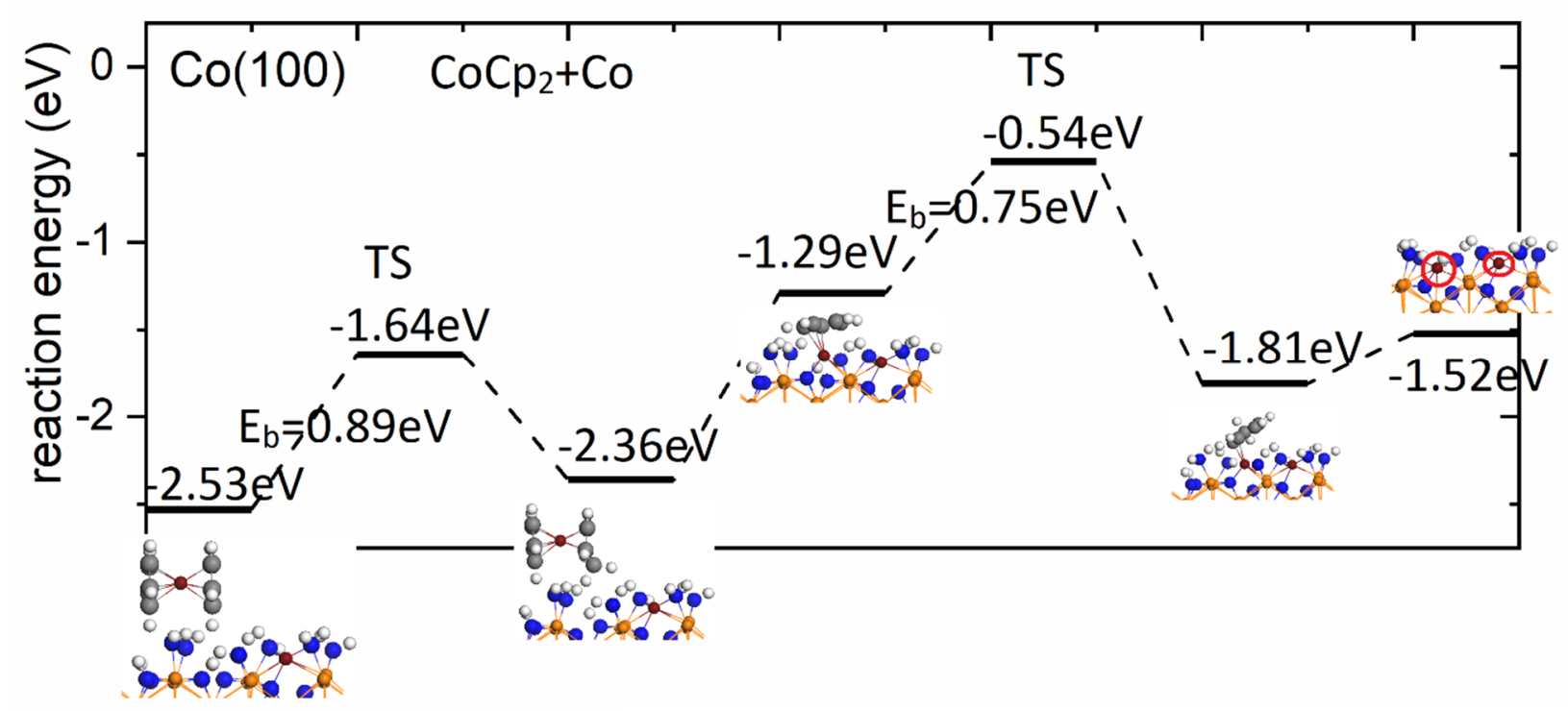

Figure 8. The plotted metal precursor reaction pathway on $\operatorname{Co}(100)$ surface with $\mathrm{CoCp}_{2}$ reaction with one Co atom deposited on the surface. The substrate Co atom is represented by orange colour and the Co atom from metal precursor $\mathrm{CoCp}_{2}$ is represented by wine red colour. Carbon, nitrogen and hydrogen atoms are represented by grey, blue and white colour, respectively.

Table 7. The calculated activation barriers for first and second hydrogen steps on $\mathrm{NH}_{\mathrm{x}^{-}}$ terminated $\mathrm{Co}(100)$ surface with one precursor $\mathrm{CoCp}_{2}$, two precursors $\mathrm{CoCp}_{2}+\mathrm{CoCp}_{2}$, and one precursor and one Co atom deposited on the surface $\mathrm{Co}+\mathrm{CoCp} 2$.

\section{Barriers/eV}

\begin{tabular}{cccc} 
& $\mathrm{CoCp}_{2}$ & $\mathrm{CoCp}_{2}+\mathrm{CoCp}_{2}$ & $\mathrm{Co}+\mathrm{CoCp}_{2}$ \\
\hline $1^{\text {st }}$ hydrogen transfer & 0.52 & No barrier & 0.89 \\
$2^{\text {nd }}$ hydrogen transfer & 0.85 & 0.79 & 0.75 \\
\hline
\end{tabular}




\subsection{Final structures after metal precursor pulse on Co (001) and (100) surfaces at ALD operating condition}

Based on the discussion in section 3.3, on the $\operatorname{Co}(001)$ surface, the preferred termination is the $\mathrm{CoCp}$ fragment. With this in mind, we consider the saturation coverage of CoCp fragments on $\mathrm{Co}(001)$ to determine the maximum coverage of $\mathrm{CoCp}$ after the metal precursor pulse. The results are summarized in Figure 9. We see that at most three CoCp fragments can be adsorbed on $\mathrm{NH}_{\mathrm{x}-}$ terminated $\mathrm{Co}(001)$ surface, which results in a coverage of $3.03 \mathrm{CoCp} / \mathrm{nm}^{2}$.

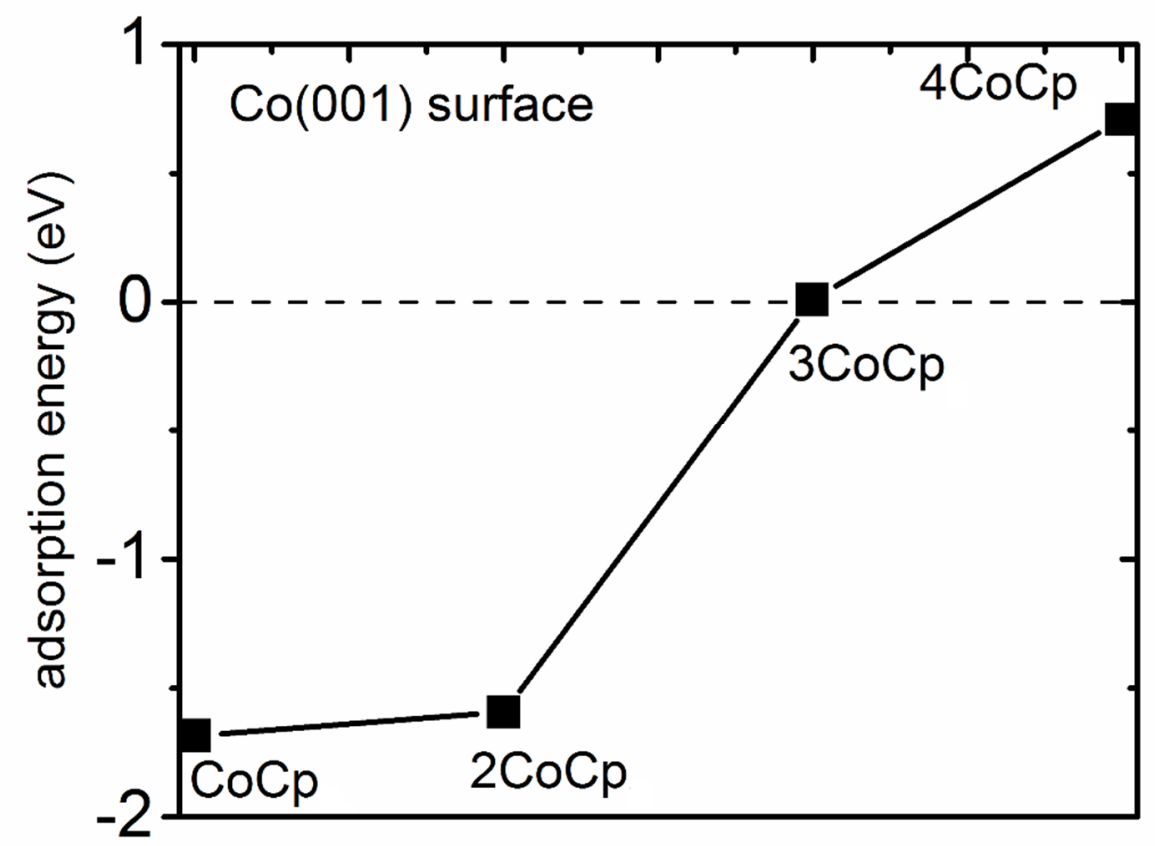

Figure 9. The adsorption energies of $\mathrm{CoCp}$ fragments on $\mathrm{NH}_{\mathrm{x}}$-terminated $\mathrm{Co}(001)$ surface at various coverages.

On the $\operatorname{Co}(100)$ surface, the channel hydrogen atoms are involved in the hydrogen transfer steps and the two $\mathrm{Cp}$ ligands are eliminated with hydrogen transfer, $\mathrm{CpH}$ formation and desorption. At ALD operating condition, the $\mathrm{NHx}$-termination is $6 \mathrm{NH}+6 \mathrm{NH}_{2}$. In total, three Co atoms are 
deposited on the surface. To explore if the surface $\mathrm{H}$ atoms can be consumed in the $\mathrm{Co}(\mathrm{Cp})_{2}$ pulse, we adsorb one $\mathrm{CoCp}_{2}$ precursor on a structure in which all channel $\mathrm{H}$ atoms have been lost to study the energetics of hydrogen transfer via surface $\mathrm{H}$ from $\mathrm{NH}_{2}$. The calculated reaction pathway is shown in Figure 10.

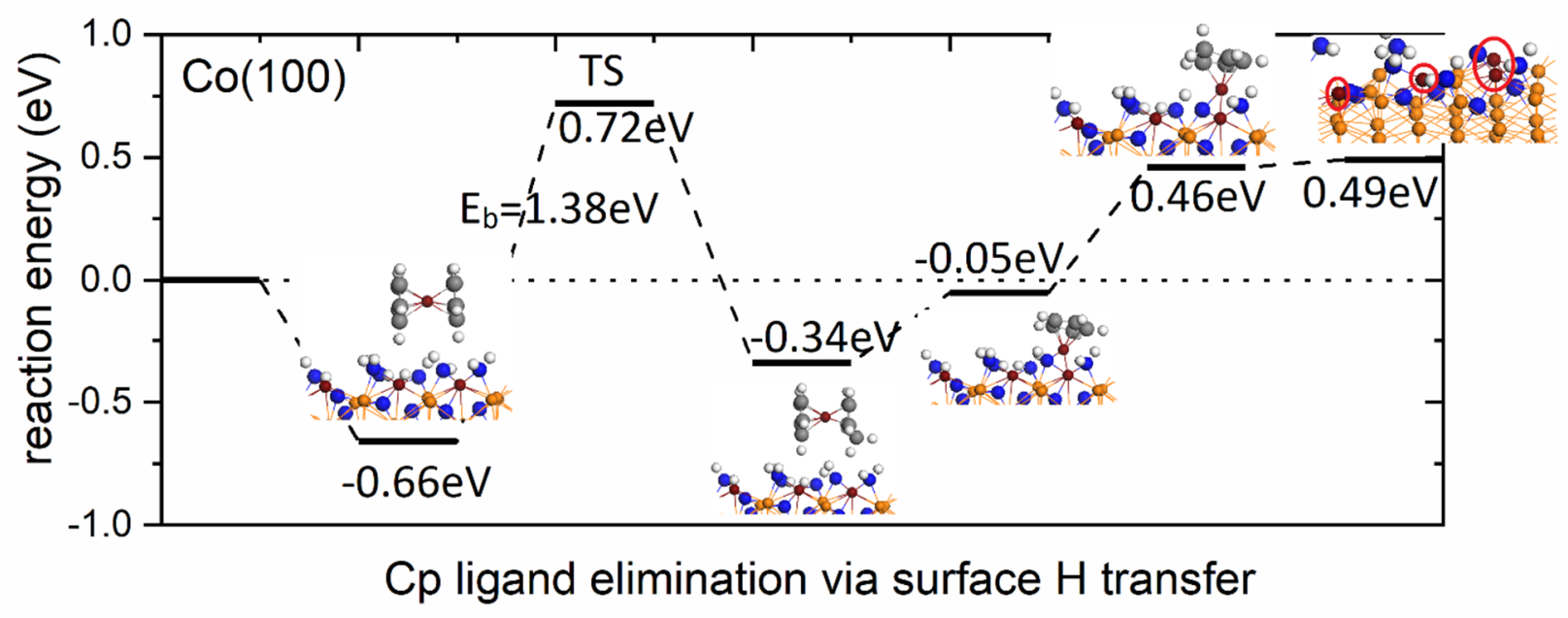

Figure 10. The plotted metal precursor reaction pathway on $\operatorname{Co}(100)$ surface with Cp ligand elimination via surface hydrogen transfer. The substrate Co atom is represented by orange colour and the Co atom from metal precursor $\mathrm{CoCp}_{2}$ is represented by wine red colour. Carbon, nitrogen and hydrogen atoms are represented by grey, blue and white colour, respectively.

With only surface $\mathrm{H}$ present, a $\mathrm{CoCp} 2$ precursor has a moderate adsorption strength with a computed adsorption energy of $-0.66 \mathrm{eV}$. The first hydrogen transfer is endothermic by $0.32 \mathrm{eV}$ and has a high barrier of $1.38 \mathrm{eV}$. After desorption of $\mathrm{CpH}$, the second hydrogen transfer is not favoured as the reaction energy is endothermic. Compared with channel hydrogen transfer, the $\mathrm{Cp}$ ligand elimination via surface hydrogen transfer is endothermic and has high activation barrier. 
Thus, we concluded that the reaction will stop after all channel $\mathrm{H}$ atoms are consumed. The final structure on $\operatorname{Co}(100)$ surface shows Co atoms deposited on the surface with the coverage of 3.33 $\mathrm{Co} / \mathrm{nm}^{2}$. The final terminations after metal precursor pulse on Co (001) and (100) surfaces are shown in Figure 11. The reported growth rate of PE-ALD of Co using $\mathrm{CoCp}_{2}$ and N-plasma varies from $0.26 \AA$ \&/cycle to $0.97 \AA /$ cycle. ${ }^{14,17-18}$ Any remaining $\mathrm{Cp}$ ligands and $\mathrm{NH}_{\mathrm{x}}$ species can be eliminated during the next N-plasma step.

(a)

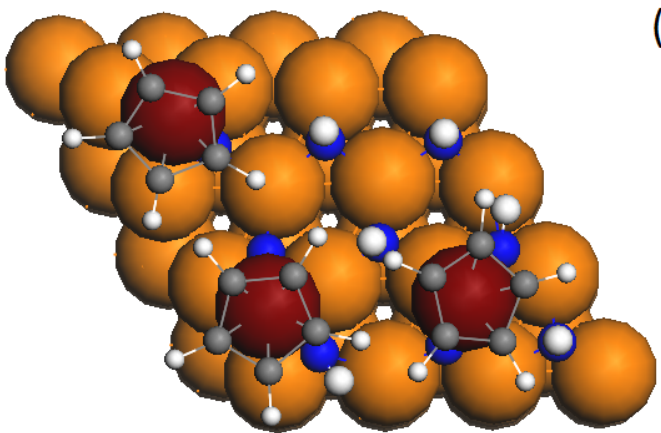

(b)

Co(001) surface, CoCp fragment terminations

(c)

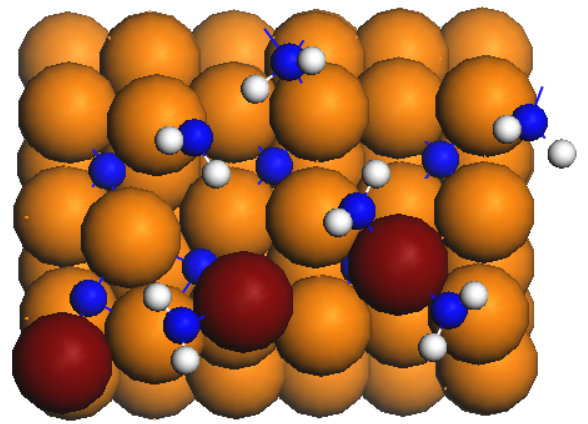

(d)

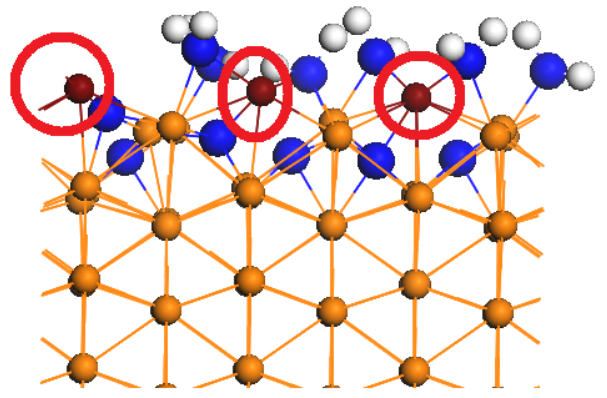

\section{Co(100) surface, Co terminations}

Figure 11. The configurations of final terminations after metal precursor pulse on $\mathrm{Co}(001)$ surface with (a) top view, and (b) side view, and $\operatorname{Co}(100)$ surface with (c) top view, and (d) side view. The substrate Co atom is represented by orange colour and the Co atom from metal precursor $\mathrm{CoCp}_{2}$ 
is represented by wine red colour. Carbon, nitrogen and hydrogen atoms are represented by grey, blue and white colour, respectively.

\section{Discussion}

The deposition of Co thin film using a $\mathrm{CoCp}_{2}$ precursor has been demonstrated experimentally. ${ }^{6}$, ${ }^{18,38-39}$ In plasma ALD studies, the co-reactants are $\mathrm{NH}_{3}$ plasma or a mixture of $\mathrm{N}_{2}$ and $\mathrm{H}_{2}$ plasma. The reported growth per cycle (GPC) and Co thin film resistivity varies with operating temperature and co-reactants. For example, when the $\mathrm{NH}_{3}$ plasma is used, at a deposition temperature of $300^{\circ} \mathrm{C}$, the GPC and resistivity were $0.48 \square$ and $10 \mu \Omega \mathrm{cm}$, respectively. ${ }^{14}$ In another study with a coreactant of $\mathrm{N}_{2} / \mathrm{H}_{2}$ plasma, the GPC was in the range of $0.26 \square$ to $0.65 \square$ for deposition temperatures in the range of $150^{\circ} \mathrm{C}$ to $450^{\circ} \mathrm{C}$. The reported resistivity was $18 \mu \Omega \mathrm{cm} \cdot{ }^{17}$ It was found that a small amount of $\mathrm{N}\left(c a .2-3\right.$ at. \%) was present in the deposited Co film when using $\mathrm{NH}_{3}$ or mixture of $\mathrm{N}_{2}$ and $\mathrm{H}_{2}$ plasma. A slightly higher amount of $\mathrm{N}(c a .4 .5$ at. \%) is present in the subsurface region. ${ }^{18}$

In this paper, we start with $\mathrm{NH}_{\mathrm{x}}$-terminated Co surfaces from ref. 31 . This is in accordance with the experimental conclusions that the $\mathrm{NH}_{\mathrm{x}}$ species play an important role in the growth mechanism. ${ }^{18,38-39}$ On a bare Co surface, the dissociation of $\mathrm{CoCp}_{2}$ precursor is difficult as a result of the strong Co-C bond. On $\mathrm{NH}_{\mathrm{x}}$-terminated Co surfaces, the $\mathrm{Cp}$ ligand is eliminated via hydrogen transfer step and will desorb the surface as $\mathrm{CpH}$. This is the key reaction mechanism during the metal precursor pulse.

From the calculation of activation barriers, the final surface termination on the $\operatorname{Co}(001)$ surface is CoCp fragments. The $\mathrm{NH}_{\mathrm{x}}$ species are not fully eliminated during this step. On the $\mathrm{Co}(100)$ 
surface, the two $\mathrm{Cp}$ ligands in $\mathrm{CoCp}_{2}$ are eliminated and the final termination is Co-terminated $\mathrm{NH}_{\mathrm{x}}$-covered surface in which Co binds to surface $\mathrm{N}$ atom. On this surface, the preference is for the channel hydrogen to be removed, leaving $\mathrm{NH}_{\mathrm{x}}$ species with surface hydrogen. These surface hydrogens are not reactive enough to promote $\mathrm{CpH}$ elimination.

When we consider multiple $\mathrm{Co}(\mathrm{Cp})_{2}$ precursors on the $\mathrm{NH}_{\mathrm{x}}$-terminated (100) and (001) surfaces, the reaction pathway is similar to that for a single precursor. On $\mathrm{Co}(001)$, the preference is for CoCp species to be present, while on $\mathrm{Co}(100), \mathrm{Cp}$ is lost, leaving Co atoms bound to the surface. The simultaneous adsorption of two $\mathrm{Co}(\mathrm{Cp})_{2}$ precursors can promote the $\mathrm{CpH}$ elimination on the $\operatorname{Co}(100)$ surface.

In the following N-plasma step, we expect that the surface CoCp fragment and surface terminating $\mathrm{NH}_{\mathrm{x}}$ species are eliminated with plasma radicals such as $\mathrm{N}, \mathrm{H}, \mathrm{NH}$ and $\mathrm{NH}_{2}$. However, the channel $\mathrm{N}$ is difficult to remove completely. This is consistent with the experimental finding of subsurface $\mathrm{N}$ atoms in Co metal. ${ }^{18,38-39}$

The study of the plasma step is beyond the scope of this paper. However, we can explore some possible reactions of the surface bound $\mathrm{NH}_{\mathrm{x}}$ species after $\mathrm{CpH}$ elimination on the $\mathrm{Co}(100)$ surface, leading to the formation of $\mathrm{N}_{2} \mathrm{H}_{4}, \mathrm{NH}_{3}$ or $\mathrm{N}_{2}$. We discuss the results of possible surface reactions for the removal of surface $\mathrm{NH}_{\mathrm{x}}$ species such as $\mathrm{N}_{\mathrm{x}} \mathrm{H}_{\mathrm{y}}$ formation at the end of metal precursor pulse.

For $\mathrm{Co}(100)$, the two $\mathrm{Cp}$ ligands are removed completely via proton transfer and $\mathrm{CpH}$ formation and desorption. The channel $\mathrm{H}$ atoms are removed during the proton transfer step. The surface $\mathrm{H}$ atoms are not removed in this mechanism due to high proton transfer barrier. The coverage of deposited Co atoms on the surface is $3.33 \mathrm{Co} / \mathrm{nm}^{2}$. We consider $\mathrm{N}_{2} \mathrm{H}_{4}$ formation, $\mathrm{NH}$ formation, and $\mathrm{H}_{2}$ formation and the results are summarized in Figure 12. The energies are discussed using 
as reference the energy of final structure of Co deposited on $\mathrm{NH}_{\mathrm{x}}$-terminated $\mathrm{Co}(100)$ surface as shown in Figure 12(a). After formation of $\mathrm{N}_{2} \mathrm{H}_{4}$ and relaxation, the resulting structure reverts to two $\mathrm{NH}_{2}$ species terminating the surface, shown in Figure 12(b). $\mathrm{NH}$ formation and $\mathrm{H}_{2}$ formation are both endothermic, with energy costs of $0.26 \mathrm{eV}$ for $\mathrm{NH}$ formation and $1.54 \mathrm{eV}$ for $\mathrm{H}_{2}$ formation respectively, compared to original final structure. These are shown in Figure 12(c)-(d). Thus, surface reactions for the removal of surface $\mathrm{NH}_{\mathrm{x}}$ species after the $\mathrm{Co}(\mathrm{Cp})_{2}$ precursor pulse are not favourable and the $\mathrm{NH}_{\mathrm{x}}$ species will be removed in the following plasma step.

(a)

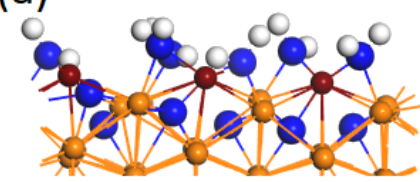

Co deposited reference energy $0.00 \mathrm{eV}$
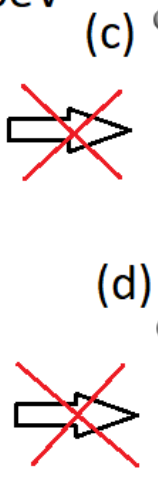

(c)

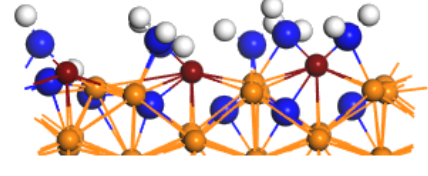

$\mathrm{NH}$ formation

(d)

(b)

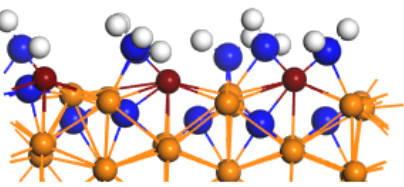

surface $\mathrm{NH}_{\mathrm{x}}$ species rearrangement

$-0.83 \mathrm{eV}$

$\mathrm{No} \mathrm{N}_{2} \mathrm{H}_{4}$ fromation

resulted $2 \mathrm{NH}_{2}$

\section{$0.26 \mathrm{eV}$}

\section{$1.54 \mathrm{eV}$}

Co(100) surface after metal precursor pulse

Figure 12. The configurations of surface reactions on $\operatorname{Co}(100)$ surface including (a) original Co deposited on $\mathrm{NHx}$-terminated surface, (b) surface $\mathrm{NH}_{\mathrm{x}}$ species rearrangement, (c) $\mathrm{NH}$ formation, and (d) $\mathrm{H}_{2}$ formation. 


\section{Conclusions}

When depositing metals, a non-oxidizing reactant is preferred because the O-source will cause contamination and oxidize the metal. The PE-ALD of Co using metal precursor and N-plasma has been demonstrated experimentally, but the reaction mechanism is not well-understood. After the $\mathrm{N}$-plasma step, the resulted metal surfaces will be $\mathrm{NH}_{\mathrm{x}}$-terminated. The nature and stability of $\mathrm{NH}_{\mathrm{x}}$-terminated metal surfaces are studied in our previous published work. ${ }^{31}$ The present work focuses on the reaction mechanism during the metal precursor pulse on the $\mathrm{NH}_{\mathrm{x}}$-terminated surfaces. These final structures and terminations after metal precursor pulse are vital to model the following plasma pulse. The surface facets will result in different precursor adsorption orientation. $\mathrm{CoCp}_{2}$ prefer up-right position with one $\mathrm{Cp}$ ring in close contact with $\mathrm{NH}_{\mathrm{x}}$-terminated (001) surface, while they are in flat position with both of the $\mathrm{Cp}$ rings anchored to zigzag channel on $\mathrm{NH}_{\mathrm{x}}$-terminated (100) surface.

The $\mathrm{Cp}$ ligands are eliminated via hydrogen transfer step and desorb from surface by forming $\mathrm{CpH}$. The surface facet plays an important role in reaction energy and barriers for hydrogen transfer step. On the $\mathrm{Co}(001)$ surface, the $\mathrm{NH}_{\mathrm{x}}$ termination is $0.56 \mathrm{ML} \mathrm{NH}$ at ALD operating condition. With single $\mathrm{CoCp}_{2}$ adsorption, only one $\mathrm{Cp}$ ligand is eliminated with moderate activation barrier at the value of $0.56 \mathrm{eV}$. With two $\mathrm{CoCp}_{2}$ adsorption, the neighbouring $\mathrm{CoCp}_{2}$ has hindered the reactivity by increasing the barrier to $0.74 \mathrm{eV}$. The final termination on $\mathrm{NH}_{\mathrm{x}}$-terminated $\mathrm{Co}(001)$ surface is CoCp fragments at the coverage of $3.03 \mathrm{CoCp} / \mathrm{nm}^{2}$.

On the $\mathrm{Co}(100)$ surface, the $\mathrm{NH}_{\mathrm{x}}$ termination is $0.67 \mathrm{ML} \mathrm{NH}$ and $0.67 \mathrm{ML} \mathrm{NH}_{2}$ at $\mathrm{ALD}$ operating condition. Channel $\mathrm{H}$ atom is more reactive than surface $\mathrm{H}$ atom. With single $\mathrm{CoCp}_{2}$ adsorption, the two Cp ligands are eliminated with moderate barriers at the value of $0.52 \mathrm{eV}$ and $0.85 \mathrm{eV}$ for the first and second hydrogen transfer. With two $\mathrm{CoCp}_{2}$ adsorption, the neighbouring $\mathrm{CoCp}_{2}$ has 
promoted the reactivity by lowering the first hydrogen transfer barrier to no barrier and the second hydrogen transfer barrier to $0.79 \mathrm{eV}$. After all channel $\mathrm{H}$ atoms are consumed, the $\mathrm{Cp}$ ligand elimination with surface $\mathrm{H}$ transfer has high barrier at the value of $1.38 \mathrm{eV}$. The final termination on $\mathrm{NH}_{\mathrm{x}}$-terminated $\mathrm{Co}(100)$ is Co atoms deposited on the surface at the coverage of $3.33 \mathrm{Co} / \mathrm{nm}^{2}$.

During the following plasma step, the remaining $\mathrm{Cp}$ ligand (if any) and surface $\mathrm{N}$ atom are eliminated by $\mathrm{N}_{\mathrm{x}} \mathrm{H}_{\mathrm{y}}$ radicals from the $\mathrm{N}$-plasma $\left(\mathrm{NH}_{3}\right.$ or mixture of $\mathrm{N}_{2}$ and $\left.\mathrm{H}_{2}\right)$. After the plasma pulse, the metal surface will be $\mathrm{NH}_{\mathrm{x}}$-terminated and the while system is ready for the next cycle. The reaction mechanism of N-plasma step is currently the subject of further study.

\section{Acknowledgements}

We acknowledge generous support from Science Foundation Ireland (SFI) through the SFI-NSFC Partnership program, Grant Number 17/NSFC/5279, NITRALD and National Natural Science Foundation of China, Grant number 51861135105. Computing resources have been generously supported by Science Foundation Ireland at Tyndall and through the SFI/HEA-funded Irish Centre for High End Computing (www.ichec.ie).

\section{References}

1. Tu, K., Recent advances on electromigration in very-large-scale-integration of interconnects. $J$. Appl. Phys. 2003, 5451-5473.

2. Greenslit, D. V.; Eisenbraun, E., Characterization of Ultrathin PEALD-Grown RuCo Films for Diffusion Barrier and Copper Direct-Plate Applications. ECS Trans. 2011, 35, 17-24. 
3. Chakraborty, T.; Eisenbraun, E. T., Microstructure analysis of plasma enhanced atomic layer deposition-grown mixed-phase RuTaN barrier for seedless copper electrodeposition. J. Vac. Sci. Technol. A 2012, 30, 020604.

4. Miikkulainen, V.; Leskelä, M.; Ritala, M.; Puurunen, R. L., Crystallinity of inorganic films grown by atomic layer deposition: Overview and general trends. J. Appl. Phys. 2013, 113, 2.

5. Johnson, R. W.; Hultqvist, A.; Bent, S. F., A brief review of atomic layer deposition: from fundamentals to applications. Mater. Today 2014, 17, 236-246.

6. Kaloyeros, A. E.; Pan, Y.; Goff, J.; Arkles, B., Review-Cobalt Thin Films: Trends in Processing Technologies and Emerging Applications. ECS J. Solid State Sci. 2019, 8, P119-P152.

7. George, S. M., Atomic layer deposition: an overview. Chem. Rev. 2009, 110, 111-131.

8. Profijt, H.; Potts, S.; Van de Sanden, M.; Kessels, W., Plasma-assisted atomic layer deposition: basics, opportunities, and challenges. J. Vac. Sci. Technol. A 2011, 29, 050801.

9. Oviroh, P. O.; Akbarzadeh, R.; Pan, D.; Coetzee, R. A. M.; Jen, T. C., New development of atomic layer deposition: processes, methods and applications. Sci. Technol. Adv. Mater. 2019, 20, 465-496.

10. Kim, H., Atomic layer deposition of metal and nitride thin films: Current research efforts and applications for semiconductor device processing. J. Vac. Sci. Technol. B 2003, 21, 2231-2261.

11. Knisley, T. J.; Kalutarage, L. C.; Winter, C. H., Precursors and chemistry for the atomic layer deposition of metallic first row transition metal films. Coordin. Chem. Rev. 2013, 257, 3222-3231.

12. Kim, H., Area selective atomic layer deposition of cobalt thin films. ECS Trans. 2008, 16, 219225.

13. Lim, B. S.; Rahtu, A.; Gordon, R. G., Atomic layer deposition of transition metals. Nat. Mater. 2003, 2, 749.

14. Kim, H., High-quality cobalt thin films by plasma-enhanced atomic layer deposition. Electrochem. Solid-State Lett. 2006, 9, G323-G325.

15. Kim, K.; Lee, K.; Han, S.; Jeong, W.; Jeon, H., Characteristics of cobalt thin films deposited by remote plasma ALD method with dicobalt octacarbonyl. J. Electrochem. Soc. 2007, 154, H177-H181.

16. Zhu, B.; Ding, Z.-J.; Wu, X.; Liu, W.-J.; Zhang, D. W.; Ding, S.-J., Plasma-Enhanced Atomic Layer Deposition of Cobalt Films Using Co (EtCp) 2 as a Metal Precursor. Nanoscale Res. Lett. 2019, 14, 76.

17. Yoon, J.; Kim, D.; Cheon, T.; Kim, S.-H.; Kim, H., Atomic layer deposition of Co using N2/H2 plasma as a reactant. J. Electrochem. Soc. 2011, 158, H1179-H1182.

18. Vos, M. F.; van Straaten, G.; Kessels, W. E.; Mackus, A. J., Atomic Layer Deposition of Cobalt Using H2-, N2-, and NH3-Based Plasmas: On the Role of the Co-reactant. J. Phys. Chem. C 2018, 122, 22519-22529. 
19. Elliott, S. D., Atomic-scale simulation of ALD chemistry. Semicond. Sci. Tech. 2012, 27, 074008.

20. Phung, Q. M.; Pourtois, G.; Swerts, J.; Pierloot, K.; Delabie, A., Atomic Layer Deposition of Ruthenium on Ruthenium Surfaces: A Theoretical Study. J. Phys. Chem. C 2015, 119, 6592-6603.

21. Elliott, S. D.; Dey, G.; Maimaiti, Y., Classification of processes for the atomic layer deposition of metals based on mechanistic information from density functional theory calculations. J. Chem. Phys. 2017, $146,052822$.

22. Phung, Q. M.; Vancoillie, S.; Pourtois, G.; Swerts, J.; Pierloot, K.; Delabie, A., Atomic Layer Deposition of Ruthenium on a Titanium Nitride Surface: A Density Functional Theory Study. J. Phys. Chem. C 2013, 117, 19442-19453.

23. Fang, G.; Xu, L.; Cao, Y.; Li, A., Theoretical design and computational screening of precursors for atomic layer deposition. Coordin. Chem. Rev. 2016, 322, 94-103.

24. Holme, T. P.; Prinz, F. B., Atomic Layer Deposition and Chemical Vapor Deposition Precursor Selection Method Application to Strontium and Barium Precursors. J. Phys. Chem. A 2007, 111, 81478151.

25. Puurunen, R. L., Surface chemistry of atomic layer deposition: A case study for the trimethylaluminum/water process. J. Appl. Phys 2005, 97, 9.

26. Elliott, S.; Scarel, G.; Wiemer, C.; Fanciulli, M.; Pavia, G., Ozone-Based Atomic Layer Deposition of Alumina from TMA: Growth, Morphology, and Reaction Mechanism. Chem. Mater. 2006, 18, 37643773.

27. Langereis, E.; Bouman, M.; Keijmel, J.; Heil, S.; Van de Sanden, M.; Kessels, W., Plasma-assisted $\mathrm{ALD}$ of $\mathrm{A} 12 \mathrm{O} 3$ at low temperatures: reaction mechanisms and material properties. ECS Trans. 2008, 16, 247-255.

28. Rai, V. R.; Vandalon, V.; Agarwal, S., Surface reaction mechanisms during ozone and oxygen plasma assisted atomic layer deposition of aluminum oxide. Langmuir 2010, 26, 13732-13735.

29. Weckman, T.; Laasonen, K., First principles study of the atomic layer deposition of alumina by TMA-H 2 O-process. Phys. Chem. Chem. Phys. 2015, 17, 17322-17334.

30. Elliott, S. D., Mechanism, Products, and Growth Rate of Atomic Layer Deposition of Noble Metals. Langmuir 2010, 26, 9179-9182.

31. Liu, J.; Nolan, M., Coverage and Stability of NHx-Terminated Cobalt and Ruthenium Surfaces: A First-Principles Investigation. J. Phys. Chem. C 2019, 123, 25166-25175.

32. Kresse, G.; Joubert, D., From ultrasoft pseudopotentials to the projector augmented-wave method. Phys. Rev. B 1999, 59, 1758. 
33. Perdew, J. P.; Chevary, J. A.; Vosko, S. H.; Jackson, K. A.; Pederson, M. R.; Singh, D. J.; Fiolhais, C., Atoms, molecules, solids, and surfaces: Applications of the generalized gradient approximation for exchange and correlation. Phys. Rev. B 1992, 46, 6671.

34. Perdew, J. P.; Burke, K.; Ernzerhof, M., Generalized gradient approximation made simple. Phys. Rev. Lett. 1996, 77, 3865.

35. Monkhorst, H. J.; Pack, J. D., Special points for Brillouin-zone integrations. Phys. Rev. B 1976, 13, 5188.

36. Maimaiti, Y.; Elliott, S. D., Precursor Adsorption on Copper Surfaces as the First Step during the Deposition of Copper: A Density Functional Study with van der Waals Correction. J. Phys. Chem. C 2015, 119, 9375-9385.

37. Henkelman, G.; Uberuaga, B. P.; Jónsson, H., A climbing image nudged elastic band method for finding saddle points and minimum energy paths. J. Chem. Phys. 2000, 113, 9901-9904.

38. Oh, I.-K.; Kim, H., Growth mechanism of Co thin films formed by plasma-enhanced atomic layer deposition using NH3 as plasma reactant. Current Applied Physics 2017, 17, 333-338.

39. Reif, J.; Knaut, M.; Killge, S.; Winkler, F.; Albert, M.; Bartha, J. W., In vacuo studies on plasmaenhanced atomic layer deposition of cobalt thin films. Journal of Vacuum Science \& Technology A: Vacuum, Surfaces, and Films 2020, 38, 012405. 
Table of Contents Graphic

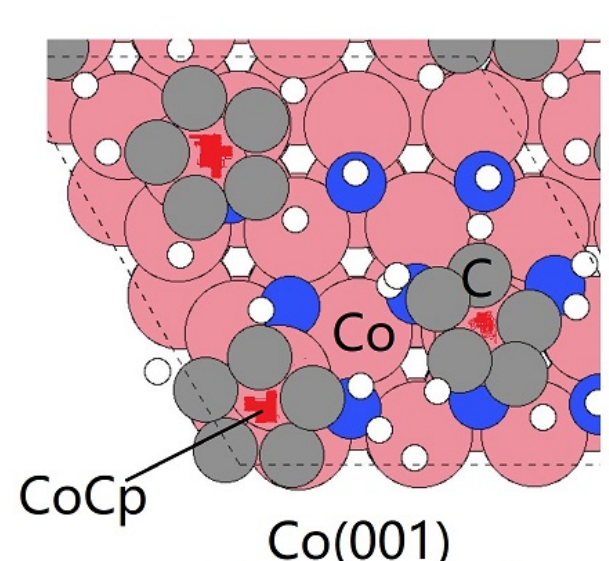

CoCp termination $3.03 \mathrm{CoCp} / \mathrm{nm}^{2}$

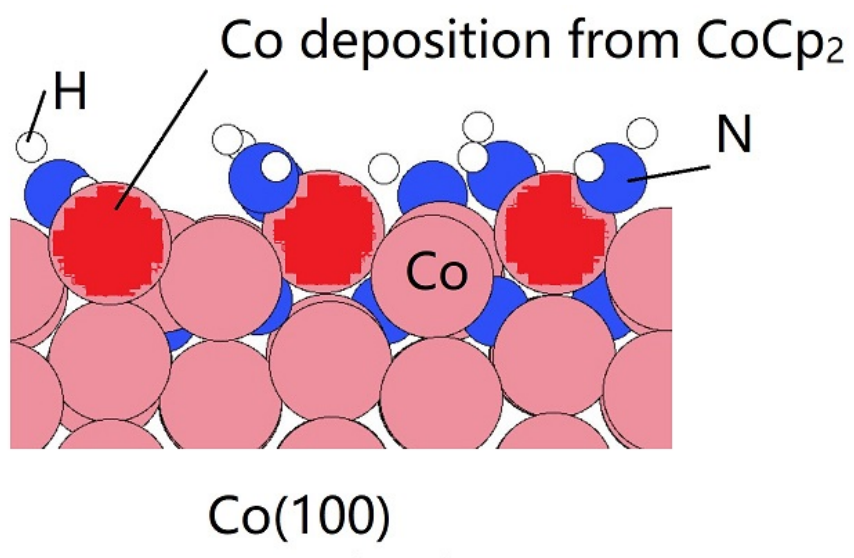

Co termination

$3.33 \mathrm{Co} / \mathrm{nm}^{2}$

Final terminations after metal precursor $\mathrm{CoCp}_{2}$ pulse 